\title{
Rheumatic Aortic Valve Disease with Mitral Stenosis-A Case Report
}

\author{
Ramachandran Muthiah \\ Thoothukudi Medical College Hospital, Thoothukudi, India \\ Email: cardioramachandran@yahoo.co.uk
}

Received 19 July 2016; accepted 28 August 2016; published 31 August 2016

Copyright (C) 2016 by author and Scientific Research Publishing Inc.

This work is licensed under the Creative Commons Attribution International License (CC BY). http://creativecommons.org/licenses/by/4.0/

(c) $\underset{\mathrm{EY}}{\mathrm{B}}$ Open Access

\begin{abstract}
Congenitally malformed aortic valves are more susceptible to valve injury due to rheumatic fever, mechanical stress of altered flow patterns, atherosclerotic risk factors and degenerative changes. Rheumatic involvement usually occurs in childhood and it is progressive leading to diffuse thickening and fibrosis at leaflet edges and thus differentiated from other patterns of valve damage. Background of this case report revealed the bicuspid nature of the aortic valve due to rheumatic commissural fusion and analysis of echocardiographic parameters in combined lesions of both aortic and mitral valves with severe $L V$ (left ventricular) dysfunction. Left ventricular (LV) and left atrial (LA) dilations predisposing to the formation of smoke (SEC-spontaneous echo contrast) in $L V$ and $L A$ as a consequence of mitral and aortic valve disease are illustrated by $2 \mathrm{D}$ echocardiographic imaging in this 41-year-old male.
\end{abstract}

\section{Keywords}

Rheumatic Bicuspid Aortic Valve, Aortic Regurgitation, Mitral Stenosis, Eccentricity Index, Smoke, Water Fall Sign, Bow and Arrow Sign

\section{Introduction}

Rheumatic heart disease (RHD) is the long-term consequence of acute rheumatic fever (ARF) and continues unabated in tropical nations. At least 15 million people are estimated to be affected by RHD worldwide up to 2005 [1]. RHD predominantly affects the left-sided cardiac valves, causing regurgitation, stenosis, or mixed hemodynamic effects. RHD is still responsible for $95 \%$ - 99.3\% of all mitral valve stenosis in individuals aged $<50$ years. Although less common than mitral valve involvement, disease of the aortic valve is a recognized manifestation of RHD. A large study of 10,000 consecutive patients with RHD shows that rheumatic aortic valve disease occurs in $4.5 \%$ of individuals aged $\leq 18$ years and in $2.8 \%$ of individuals aged $>18$ years [2]. In smaller 
series, the prevalence has been reported to be $0 \%-21.4 \%$ [3], [4]. Pathological aortic regurgitation in the absence of well defined valvular lesion such as bicuspid aortic valve or dilated aortic root is rare [5] and increased prevalence is likely to represent early RHD. Irregular or focal thickening, coaptation defect and restricted leaflet motion are the echocardiographic features of RHD in aortic valves. Excessive leaflet motion with a prevalence of prolapse constitutes $3.8 \%-59 \%$ in rheumatic aortic regurgitation.

\section{Review of Literature}

Bicuspid aortic valve may be present in as many as $1 \%-2 \%$ of the population and remain silent, found as an incidental finding on echocardiographic evaluation of the heart. Sir William Osler was the first to identify the bicuspid aortic valve as the commonest congenital anomaly of the heart [6]. The bicuspid aortic valve (BAV) was first characterized in the early $16^{\text {th }}$ century by Leonardo da Vinci [7]. Based on cusp size, three variations have been described as two cusps of equal size, unequal size and a conjoined cusp twice the size of its nonconjoined mate [8]. Thomas Peacock recognized the tendency of a BAV to become stenotic due to mechanical stress by promoting fibrosis and calcification [9]. Two-dimensional echocardiography provides accurate confirmation of a bicuspid aortic valve [10]. Edler was the first to obtain ultrasonic signals from the aortic valve [11] and subsequently Gramiak [12] described the technique of studying the aortic root routinely by echocardiography.

Embryologically, the normal right and left aortic leaflets form at the junction of the ventricular and arterial ends of the conotruncal channel. The nonseptal (posterior) leaflet cusp normally forms from additional conotruncal channel tissue. Abnormalities of this area lead to the development of a bicuspid valve, often through incomplete separation (or fusion) of valve tissue [13]. Proponents of environmental causes believe that abnormal blood flow through the aortic valve during valvulogenesis results in a failure of cusp separation. The extracellular matrix (ECM) proteins help to direct cell differentiation and cusp formation during valvulogenesis. Microfibrillar proteins fibrillin and fibulin [14], act as scaffolding for embryonic cells and regulate tissue formation in the developing aortic valves. Inadequate production of fibrillin-1 during valvulogenesis may disrupt the formation of aortic cusps resulting in a bicuspid aortic valve [15]. Defects in the gene that encode matrix elements have not yet been identified and abnormalities of gene encoding endothelial nitric oxide synthase (eNOS) may result in high incidence of BAV (bicuspid aortic valve) [16].

The bicuspid aortic valve is typically made of two unequal-sized leaflets. The morphologic patterns of bileaflet valve vary according to which commissures have fused. Abnormal neural crest migration resulting in fusion of valve cushions has been suggested as a possible explanation by which bicuspid aortic valve disease develop in humans [17]. The fusion of right and left coronary cusps (RL fusion) is the most common (80\%) pattern which is usually associated with coarctation of aorta. Fusion of right and noncoronary cusp (RN fusion-17\%) is associated with pathological changes as stenosis or insufficiency [18] in children. The fusion between the noncoronary and left coronary leaflets is less common (2\%). The severe the number of cusps, the greater is the chance that the valve is stenotic from birth. The anatomy of the bicuspid aortic valve may also influence the propensity for obstruction. Stenosis is more rapid if the aortic cusps are asymmetrical or in the anteroposterior position [19]. Rarely, the leaflets are symmetrical or there is no raphe, termed as "pure bicuspid aortic valve". However, two large studies in adults have not identified the leaflet orientation as a risk factor for late adverse events [20], [21] and a modifying role of atherosclerotic and degenerative process encountered for aortic valve disease as mostly of acquired basis. Rheumatic involvement as acquired etiology plays a role in aortic valve disease of children and adults in a similar manner irrespective of the valve leaflet malformation.

Rheumatic involvement of aortic valve results in progressive fibrosis of the leaflets with varying degree of commissural fusion, often with retraction of leaflet edges and in certain cases with calcification. As a consequence, the rheumatic aortic valve is often regurgitant and stenotic [22] and a coexistent mitral valve disease is almost always present and so this case had been reported.

\section{Case Report}

A 41-year-old male with features of heart failure was referred for echocardiography. He had a history of febrile illness with joint pains during childhood at the age of 6 years, taken penicillin prophylaxis for rheumatic fever and discontinued intermittently. He got married at the age of 26 years and had 3 children in good health. He developed symptoms of heart failure such as exertional dyspnea and orthopnea at the age of 30 years and treated with antifailure measures. He is taking digoxin $0.25 \mathrm{mg}$ once daily, frusemide $40 \mathrm{mg}$ once daily, spironolactone $25 \mathrm{mg}$ twice daily and intramuscular benzathine penicillin G injection 1.2 million units every 3 weeks. His 
symptoms get improved and continuing the same medications regularly for the past two years. His pulse rate was $78 \mathrm{bpm}$, irregular and blood pressure 120/60 mmHg. Physical examination revealed varying intensity of first heart sound, normally heard second heart sound, no additional sounds such as opening snap and third heart sound. He had a heaving apical impulse in the left $7^{\text {th }}$ intercostal space in the mid axillary line and grade 3/6 mid-diastolic murmur at the apex, an early diastolic murmur in the left sternal border most prominent in $3^{\text {rd }}$ and $4^{\text {th }}$ intercostal spaces. He had no ejection click. The peripheral signs of chronic aortic regurgitation such as wide pulse pressure, Corrigan's sign and, Hill's sign were not present due to heart failure. JVP (Jugular venous pressure) not elevated and lung fields were clear at present. Blood chemistry revealed normal and ASO (anti-streptolysin O) titer was negative. ECG revealed atrial fibrillation and LVH (left ventricular hypertrophy) as shown in Figure 1 and X-ray chest revealed left ventricular enlargement as shown in Figure 2 and a "double density sign” of LA (left atrial) enlargement in the lower right cardiac border.

Transthoracic echocardiography revealed Rheumatic aortic valve disease with mitral stenosis as shown in Figures 3-30.

Echocardiographic features of aortic valve are shown in Figures 3-17.

Echocardiographic features of mitral valve are shown in Figures 18-30.

\section{Discussion}

\subsection{Etiopathogenesis}

Congenitally, unicuspid, bicuspid, tricuspid, or even quadricuspid aortic valves may be the cause of aortic stenosis. In neonates and infants $<1$ year, unicuspid valve is the most common anomaly with fatal valvular aortic stenosis. Bicuspid aortic valves do not cause significant narrowing of the aortic orifice during childhood. In

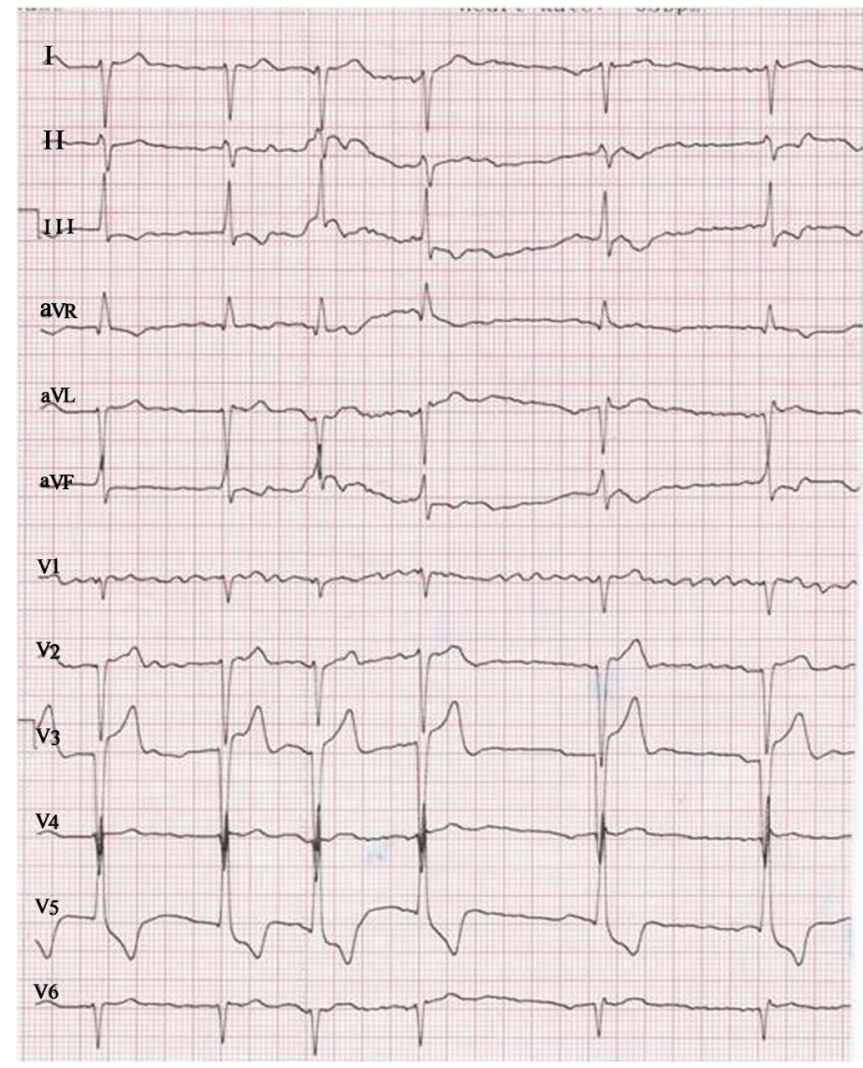

Figure 1. ECG showing atrial fibrillation and LVH and a gross increase in precordial voltage- $\mathrm{RV}_{5}+\mathrm{SV}_{2}=70 \mathrm{~mm}$ ). $\mathrm{T}$ waves inverted with ST segment depression-a left ventricular "strain pattern" in $\mathrm{V}_{5}$ correlates with the presence of dilatation and hypertrophy [23] (1 mV = $5 \mathrm{~mm}$ standardization). 


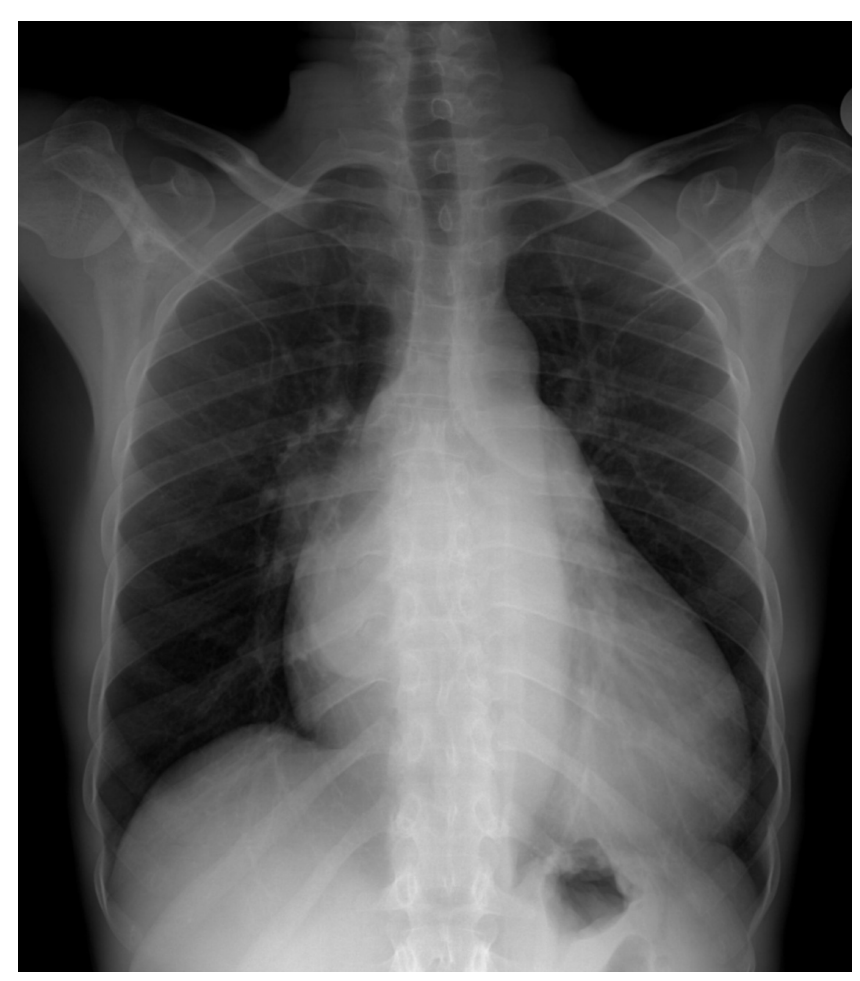

Figure 2. X-ray chest PA view showing LV (left ventricular) enlargement-a large convex left ventricle extending below the left hemidiaphragm and "double atrial shadow" of left atrial enlargement (double density sign) seen in right atrial border.

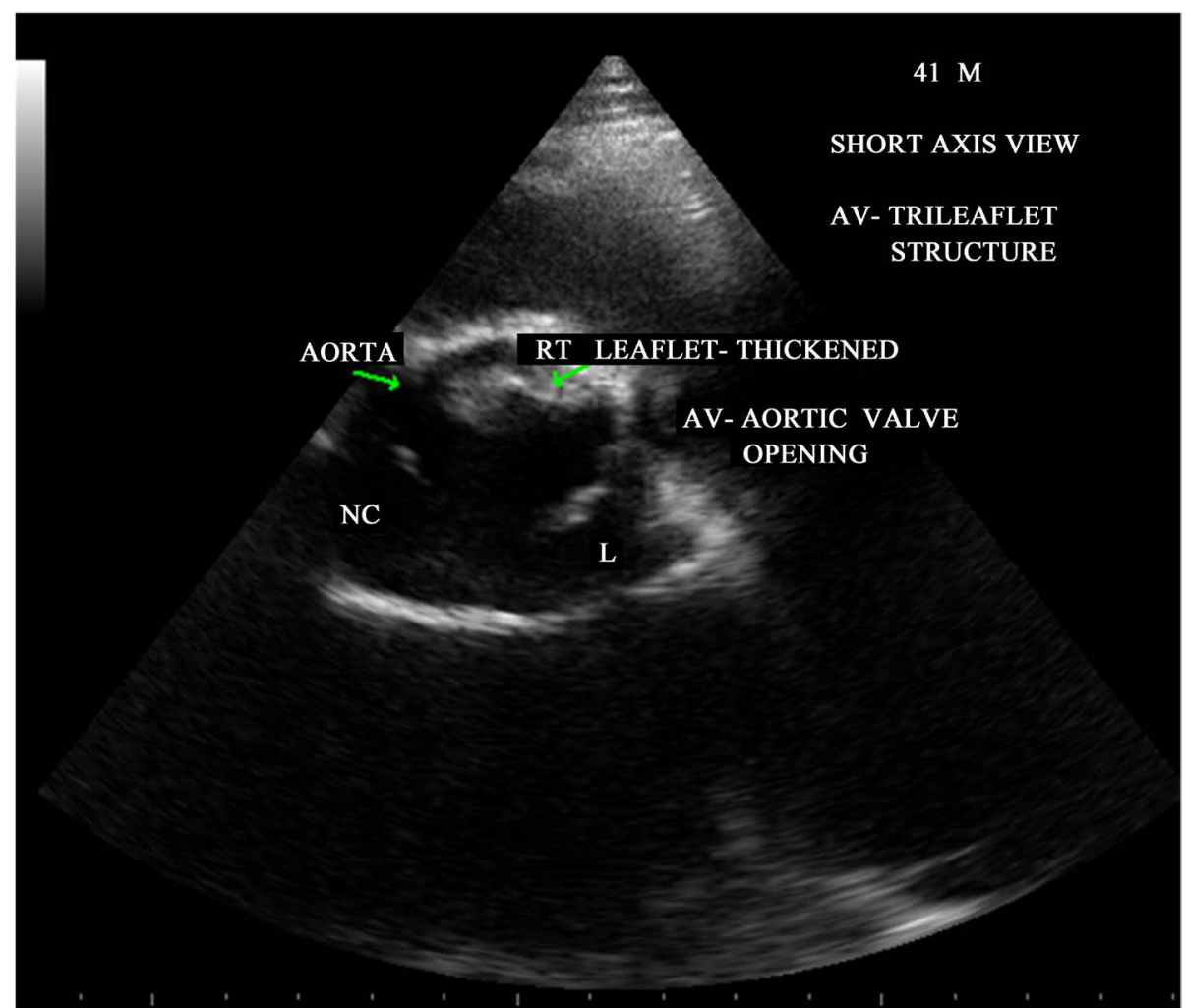

Figure 3. Short axis view showing the aortic valve as a trileaflet structure with unequal cusps. 


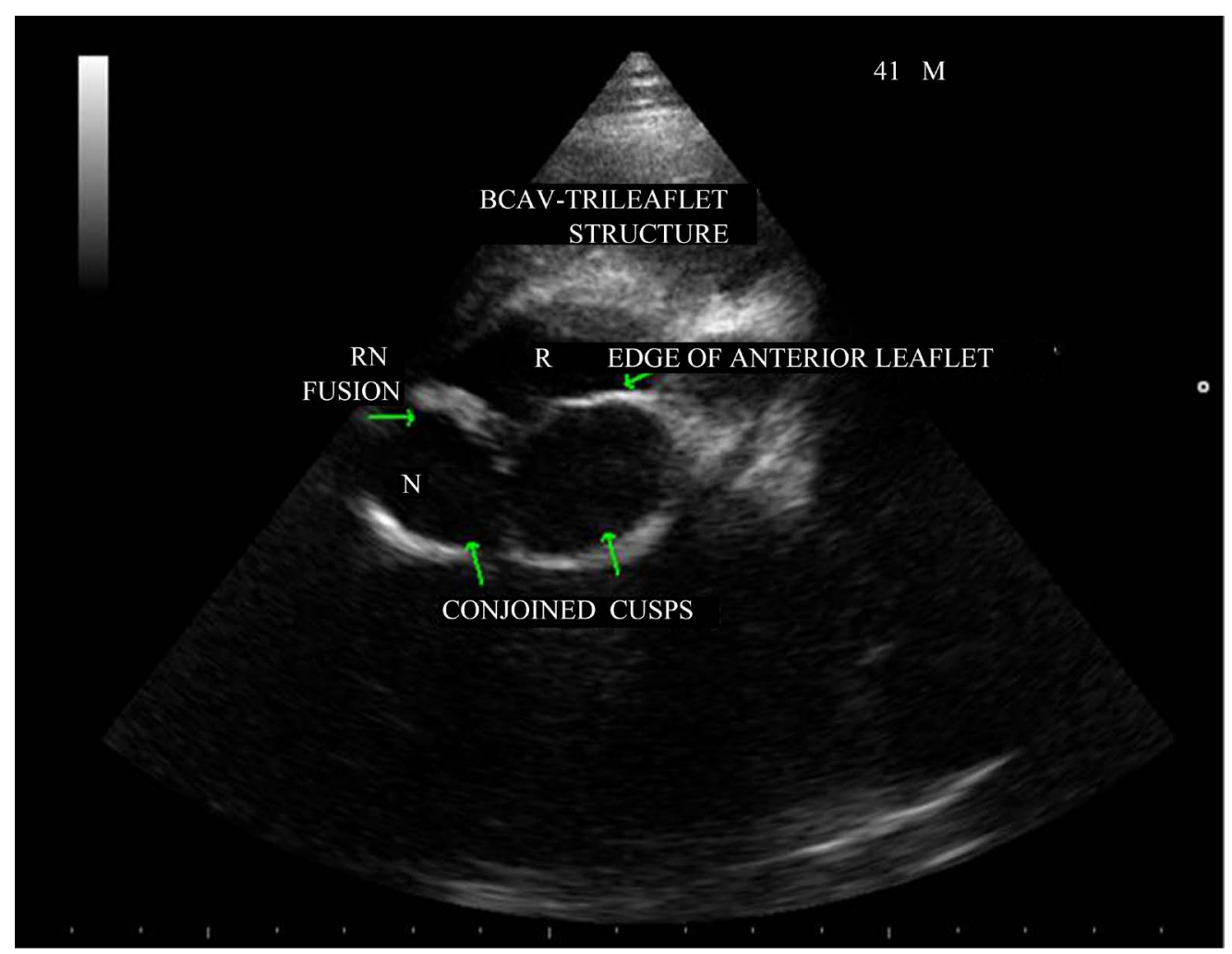

Figure 4. Short axis view showing the bicuspid configuration of the aortic valve.

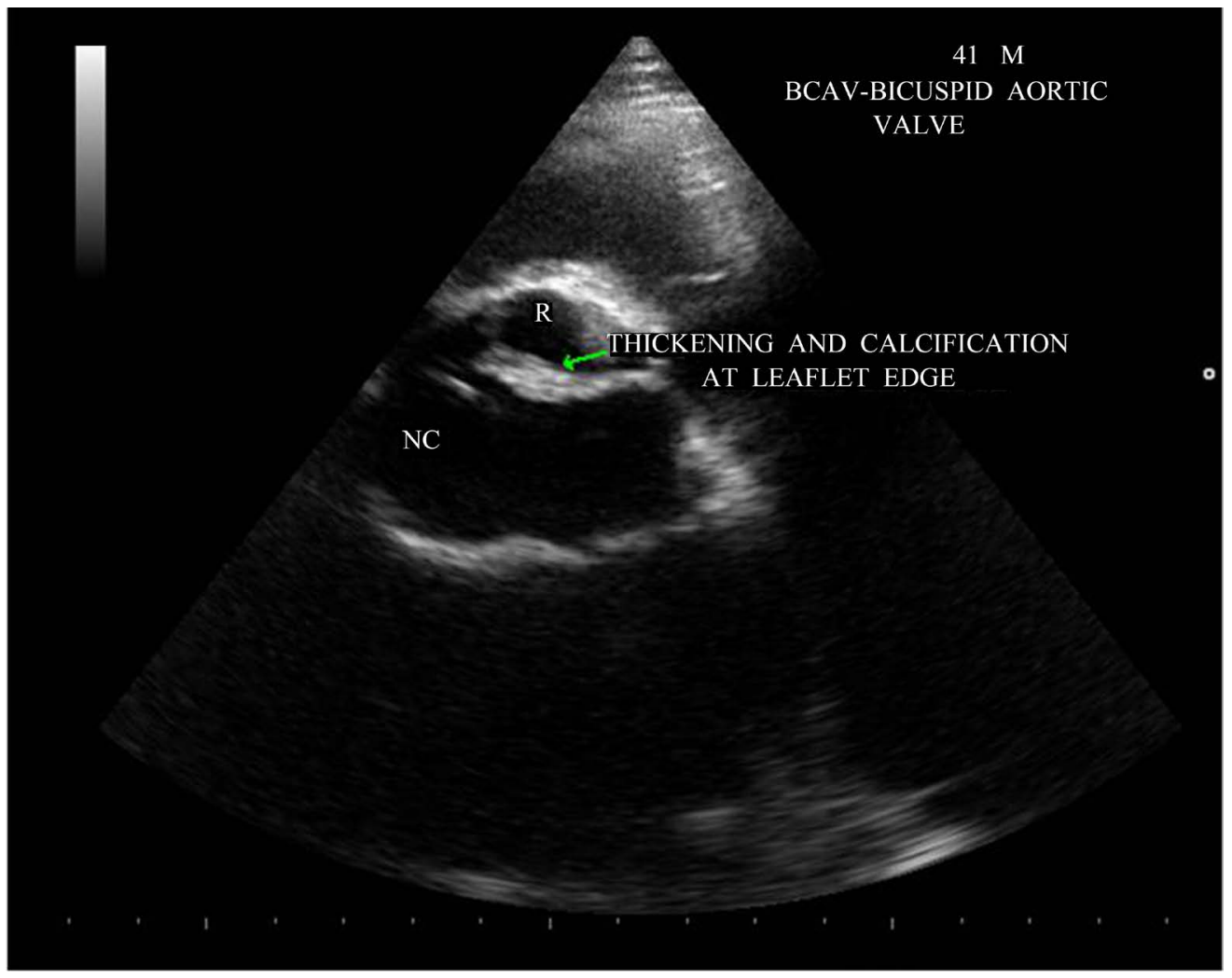

Figure 5. Short axis view showing the thickening and calcification at the anterior leaflet edge. 


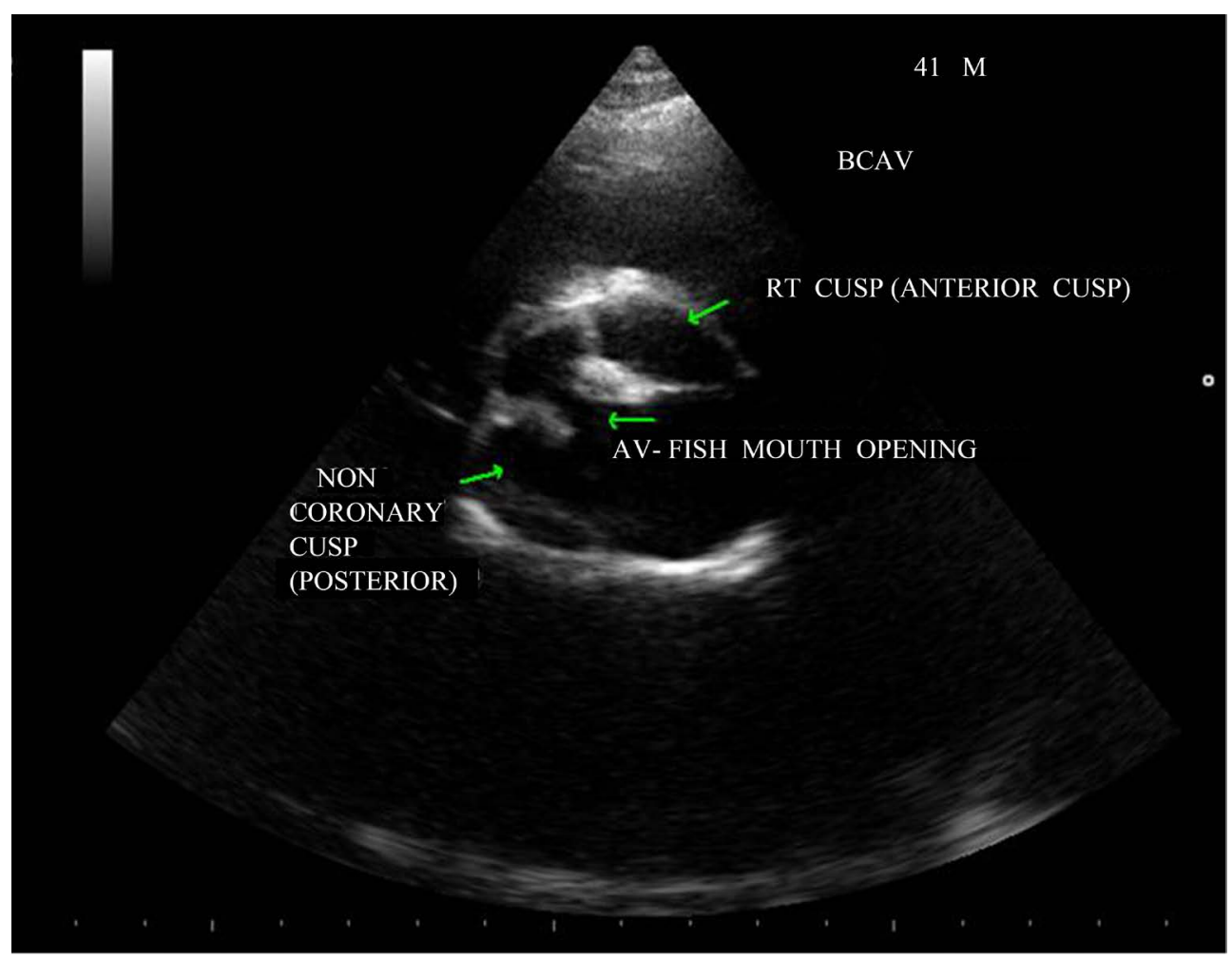

Figure 6. Short axis view showing the "fish mouth" appearance of aortic valve due to thickening and calcification.

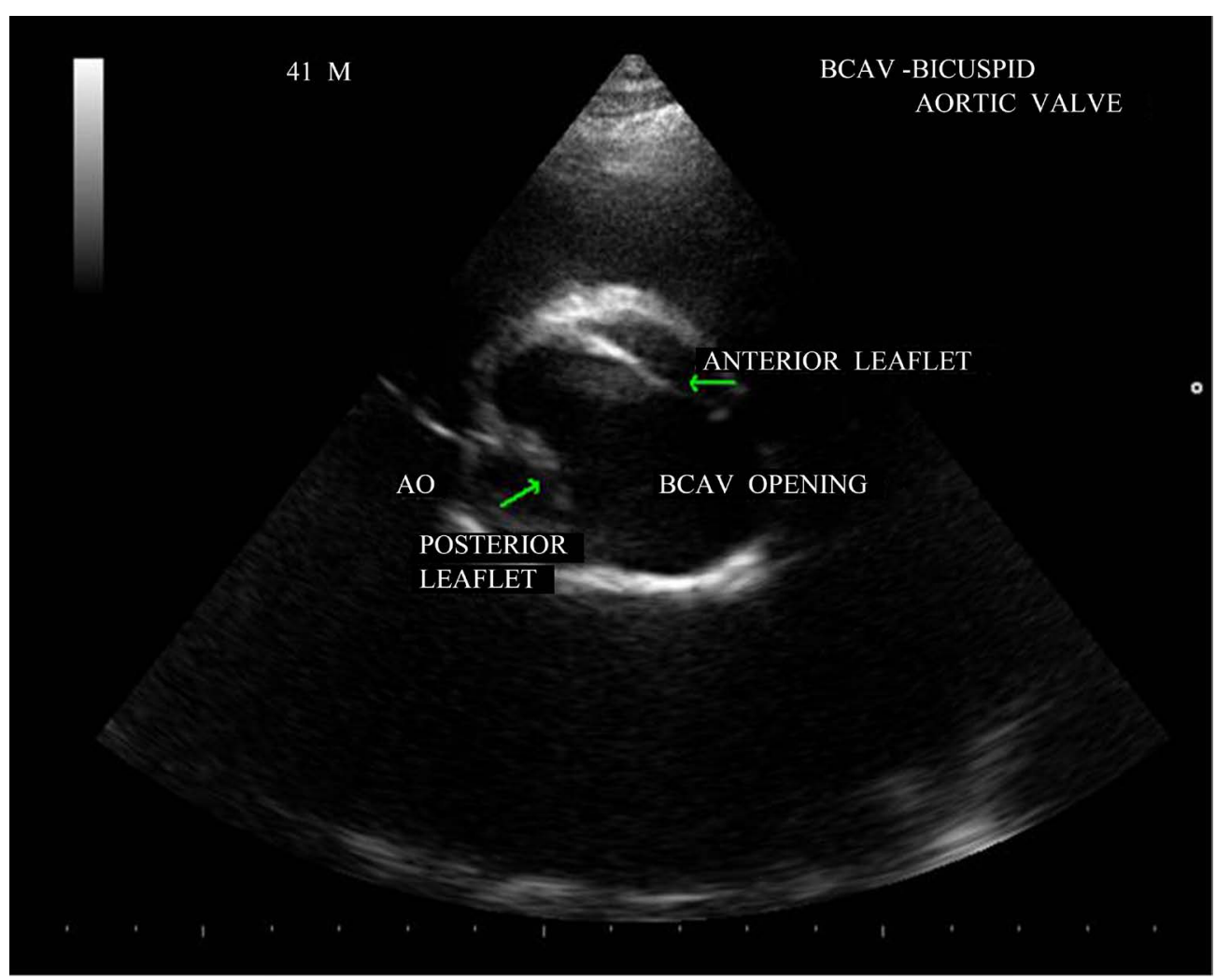

Figure 7. Short axis view showing the opening of the aortic valve with two leaflet structure. 


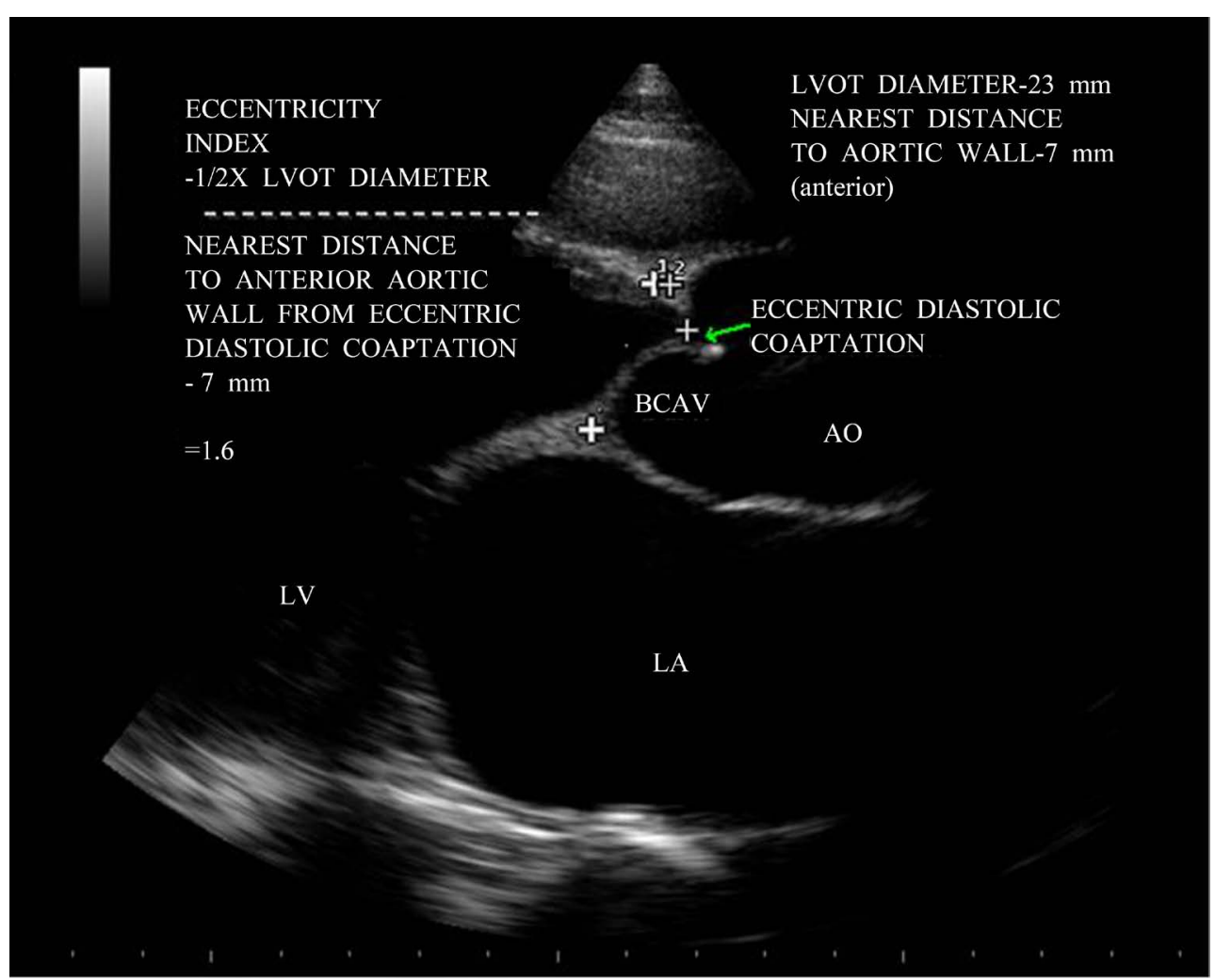

Figure 8. Parasternal long axis view showing the "eccentricity index".

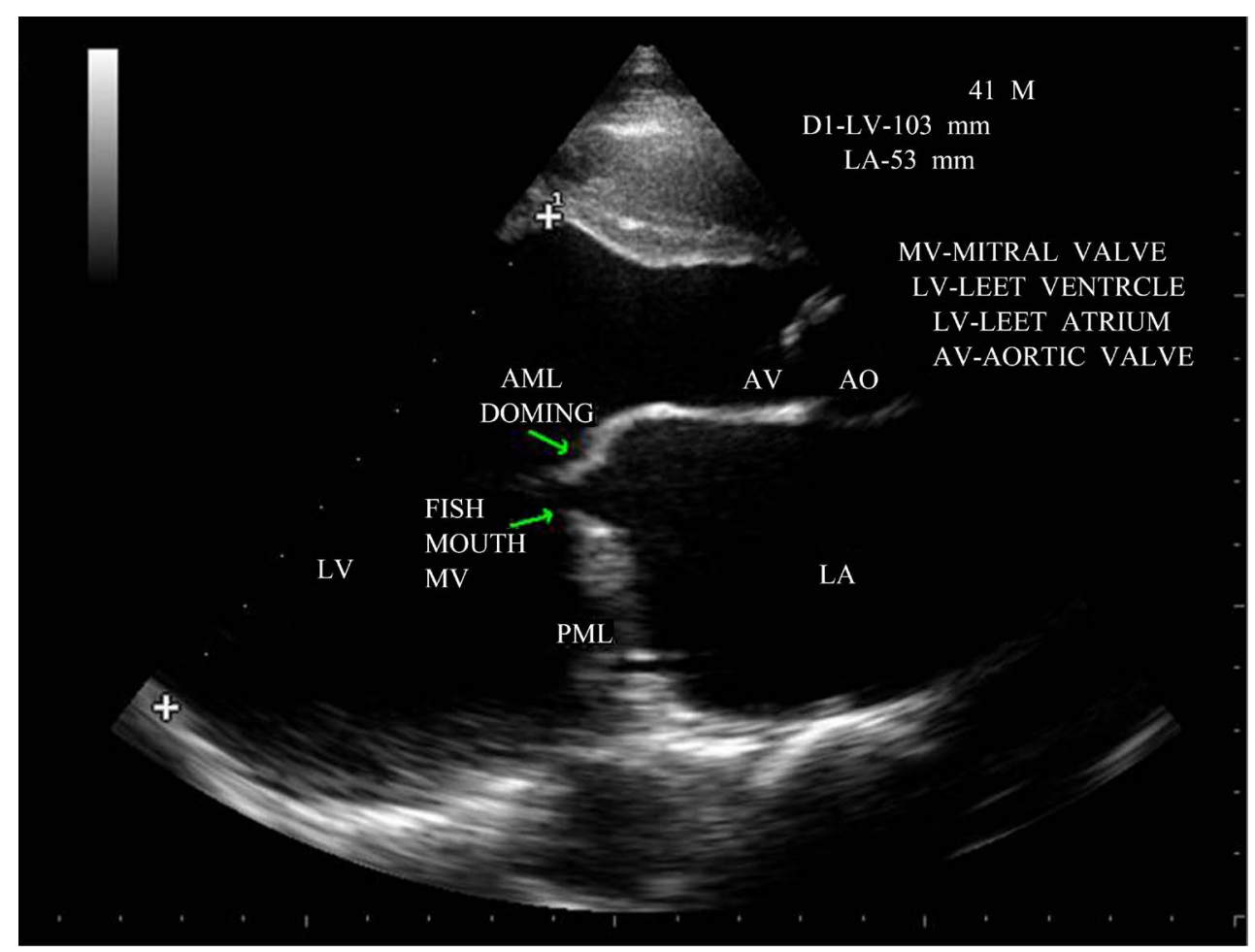

Figure 9. Parasternal long axis view showing the massive LV (left ventricular) dilatation, "doming” motion of anterior mitral leaflet (AML) and" fish-mouth opening" or "buttonhole" deformity of MV (mitral valve). 


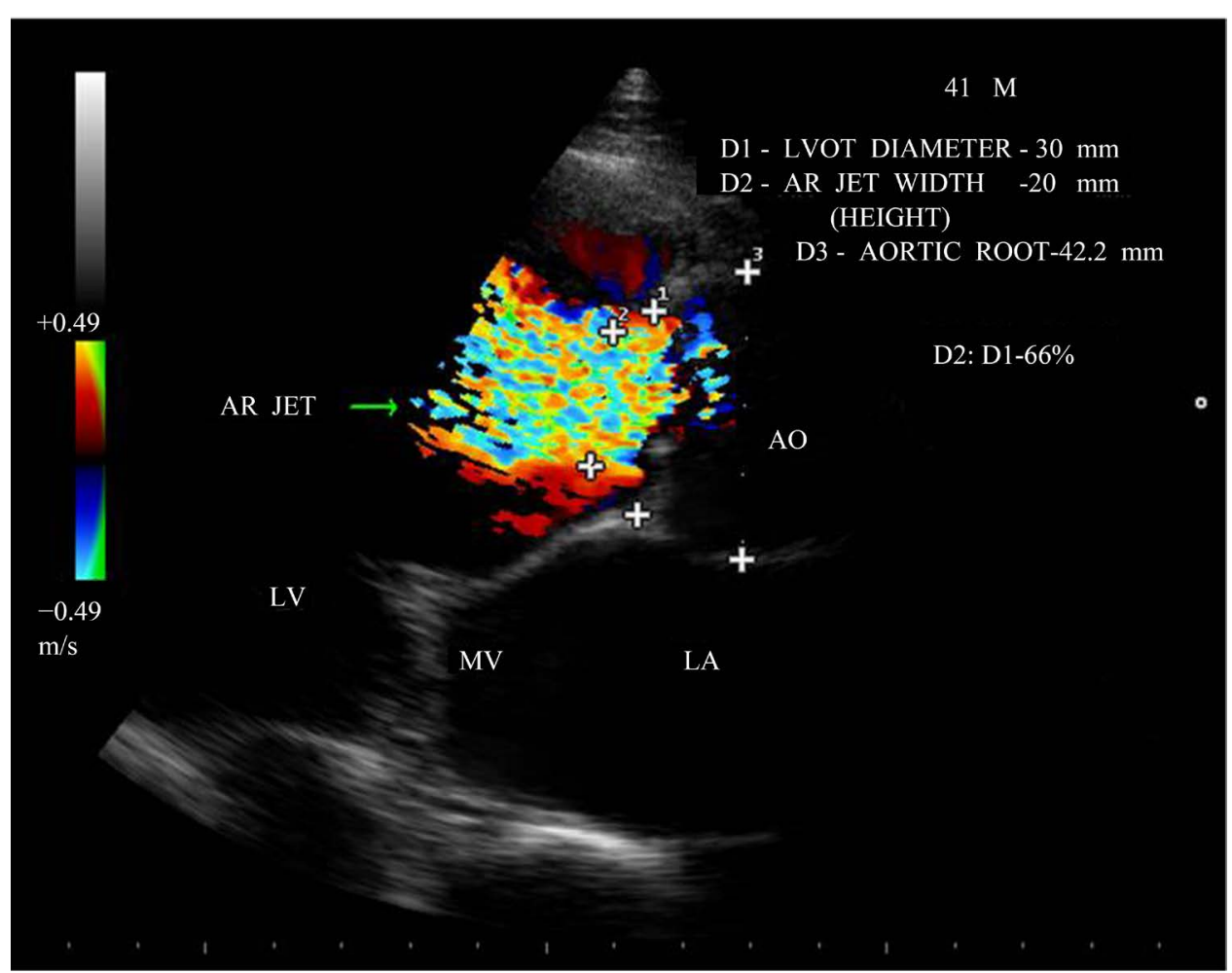

Figure 10. Parasternal long axis view showing the central AR jet in color-doppler imaging-JH/ LOVH (Jet height/left ventricular outflow tract height) ratio-66\%-severe AR.

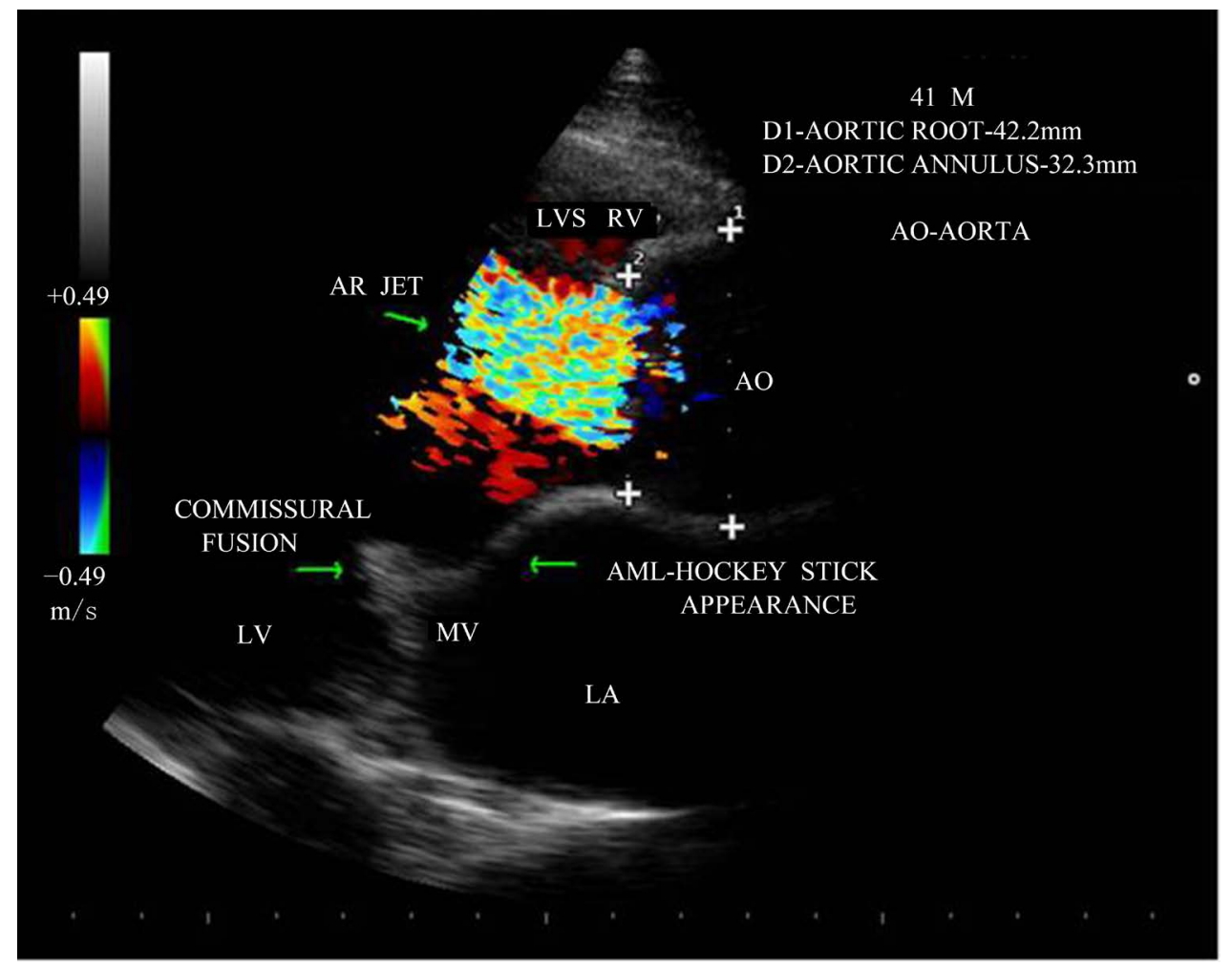

Figure 11. Parasternal long axis view showing the AR jet towards IVS (interventricular septum) and dilated aortic root- $42.2 \mathrm{~mm}$, aortic annulus- $-32.3 \mathrm{~mm}$. 


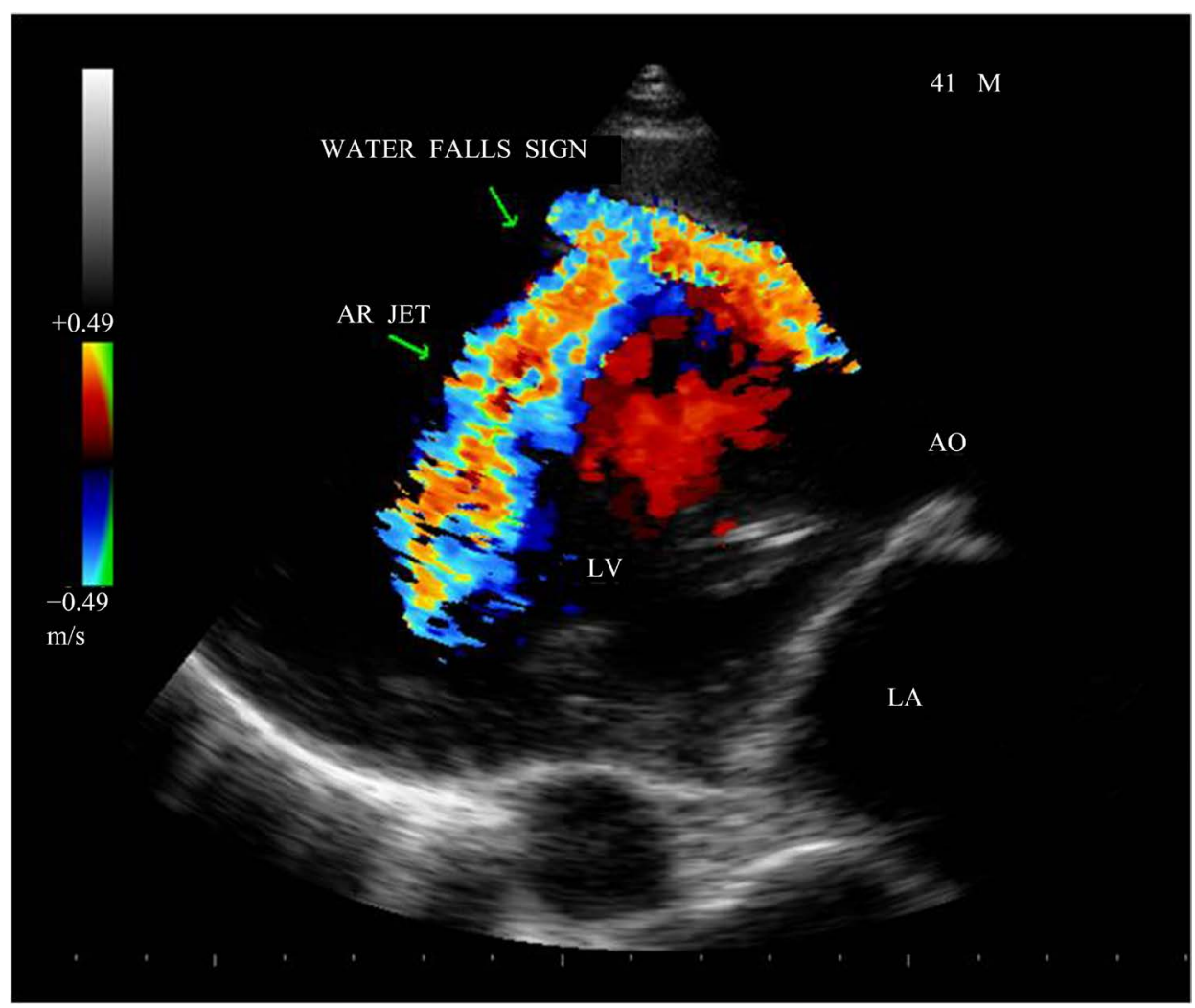

Figure 12. Parasternal long axis view showing the AR jet falling into the LV with a typical appearance of a "water fall”.

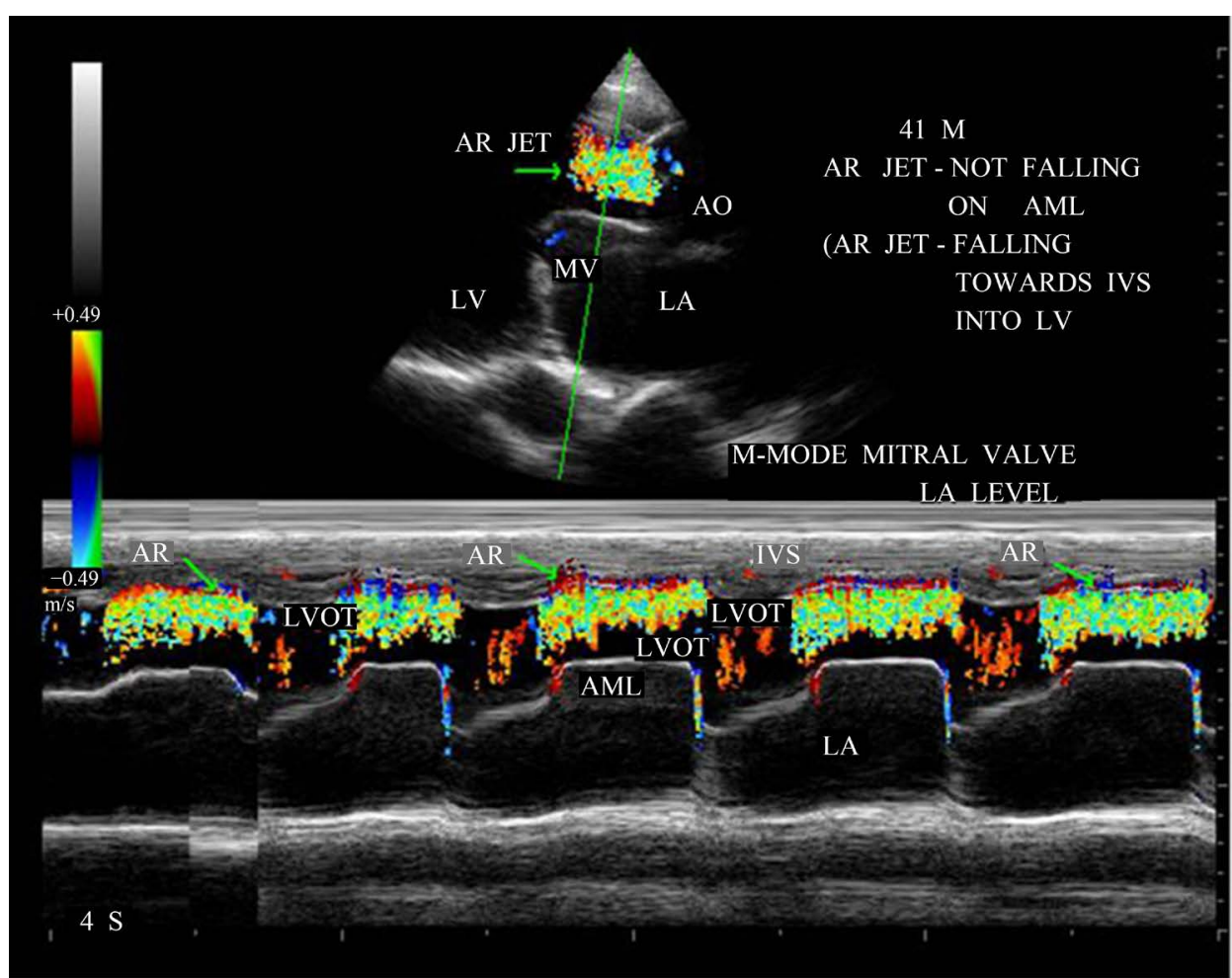

Figure 13. M-mode color doppler AR jet towards IVS at LA (left atrial) level. 


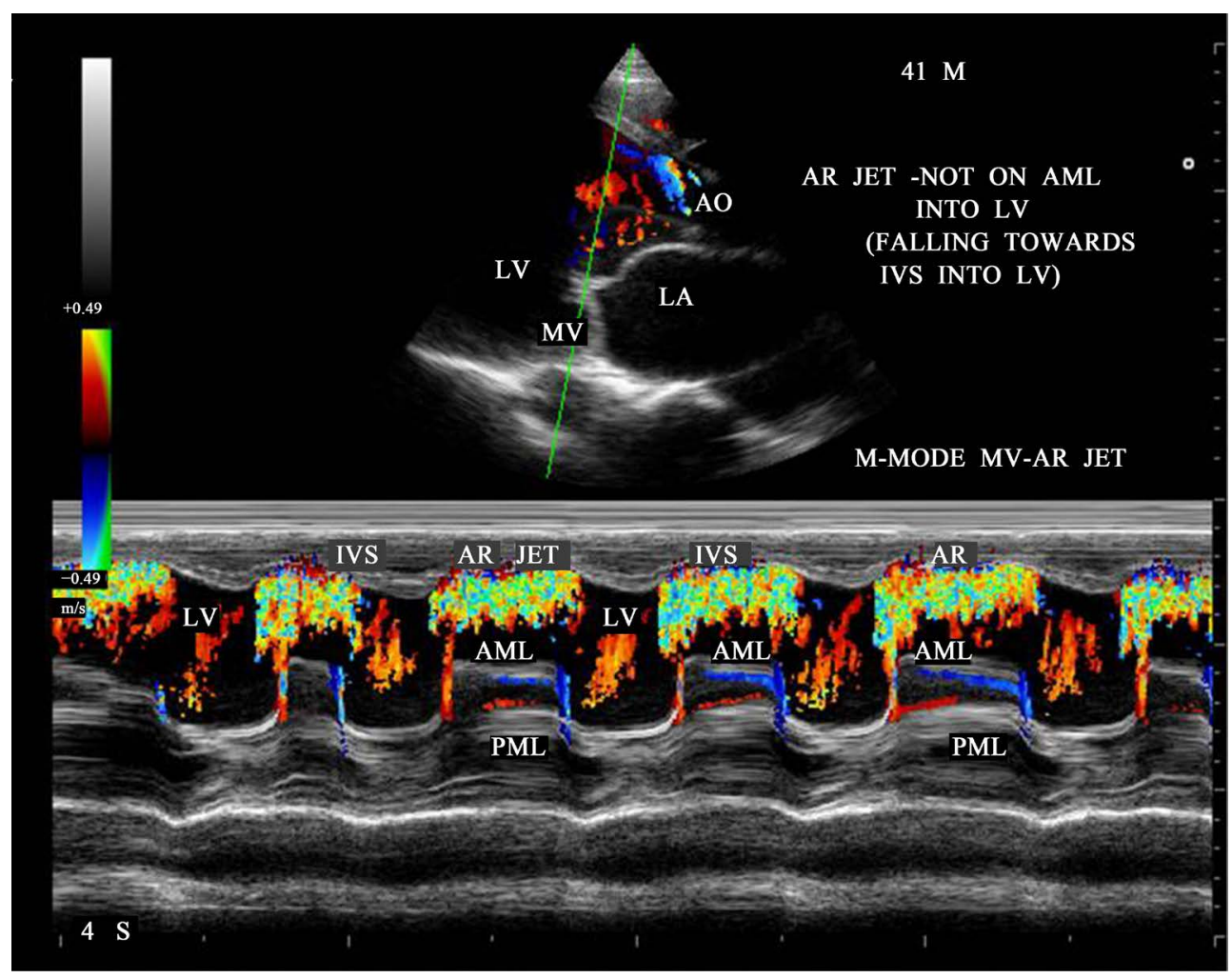

Figure 14. M-mode color doppler showing AR jet towards IVS (interventricular septum) at mitral valve level).

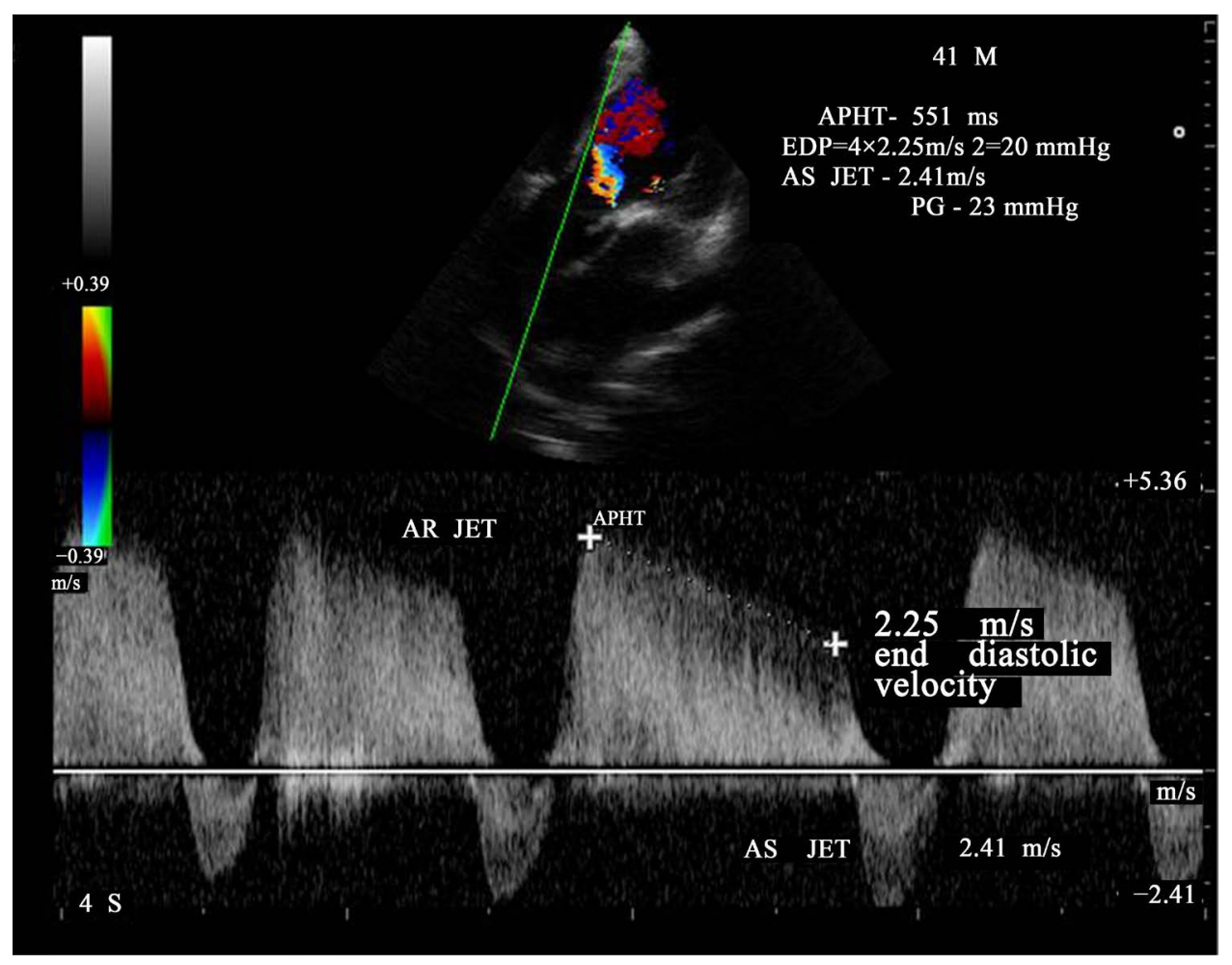

Figure 15. CW doppler imaging showing the AR jet-pressure half-time in long cycle in AF (atrial fibrillation)—flat slope of pressure decay. AS (aortic stenosis) jet. 


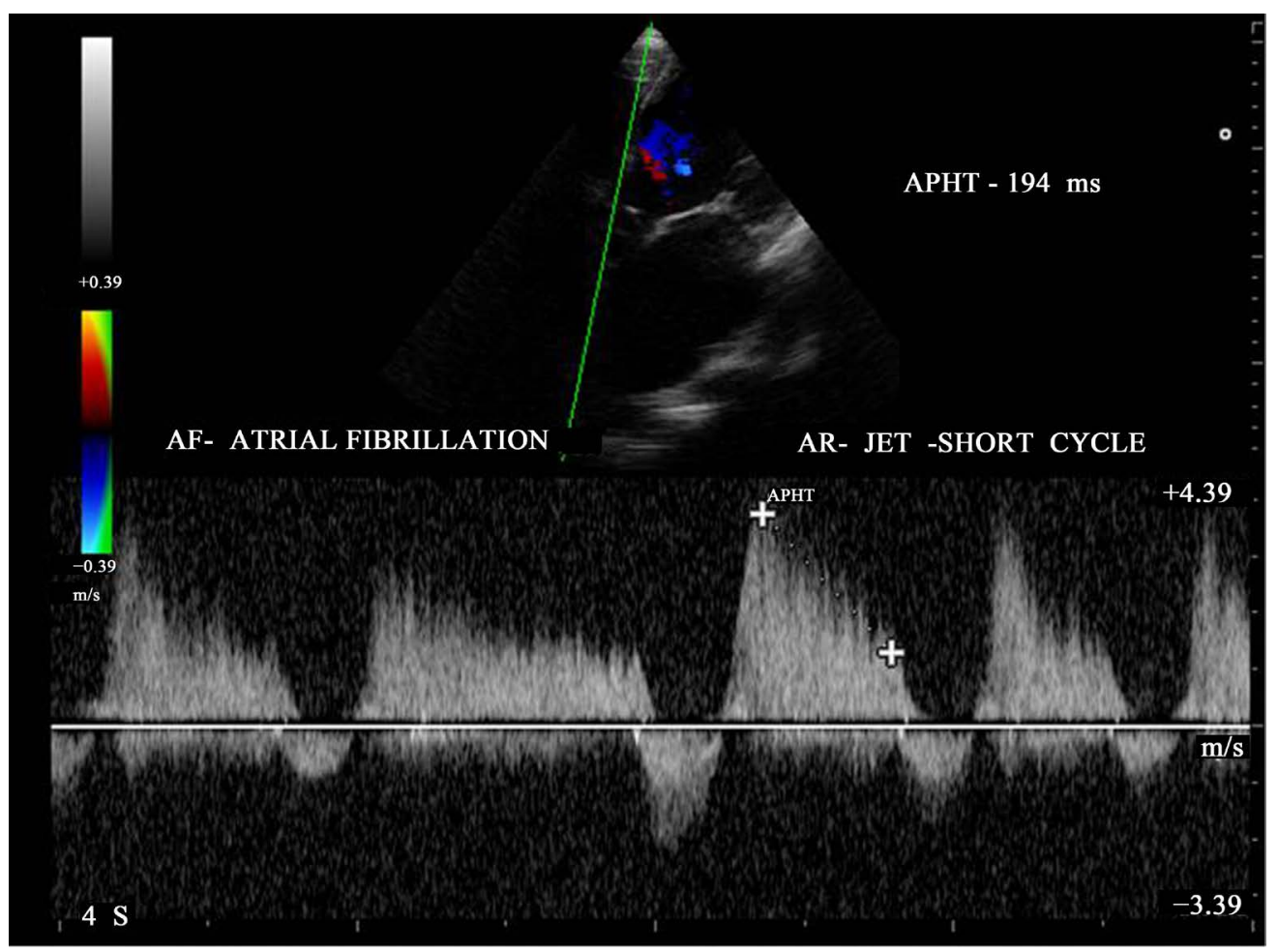

Figure 16. CW doppler imaging showing the AR jet-pressure half-time in short cycle in AF (atrial fibrillation)—steeper slope of pressure decay.

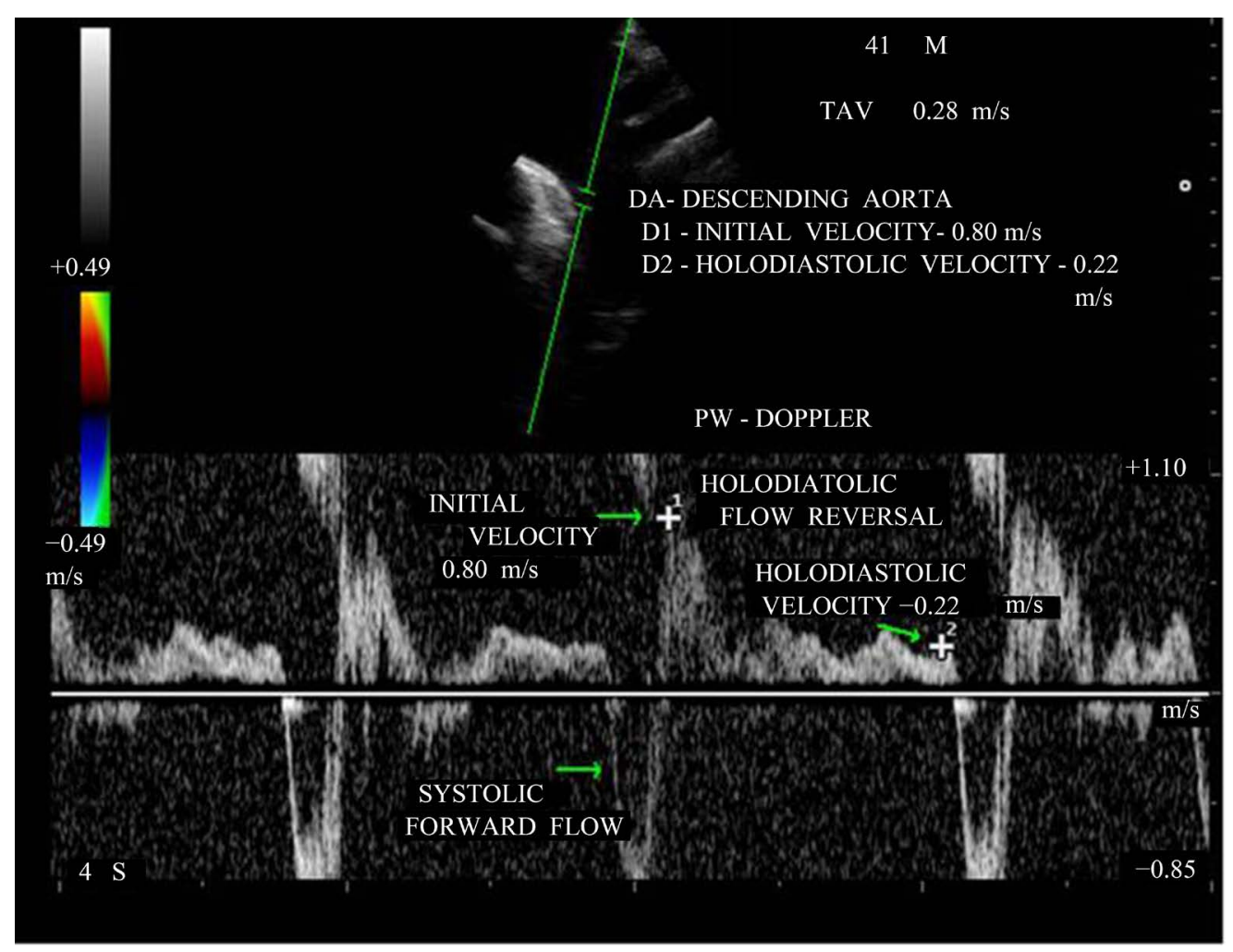

Figure 17. PW doppler showing the "holodiastolic flow reversal" in the descending aorta-suprasternal notch view). 


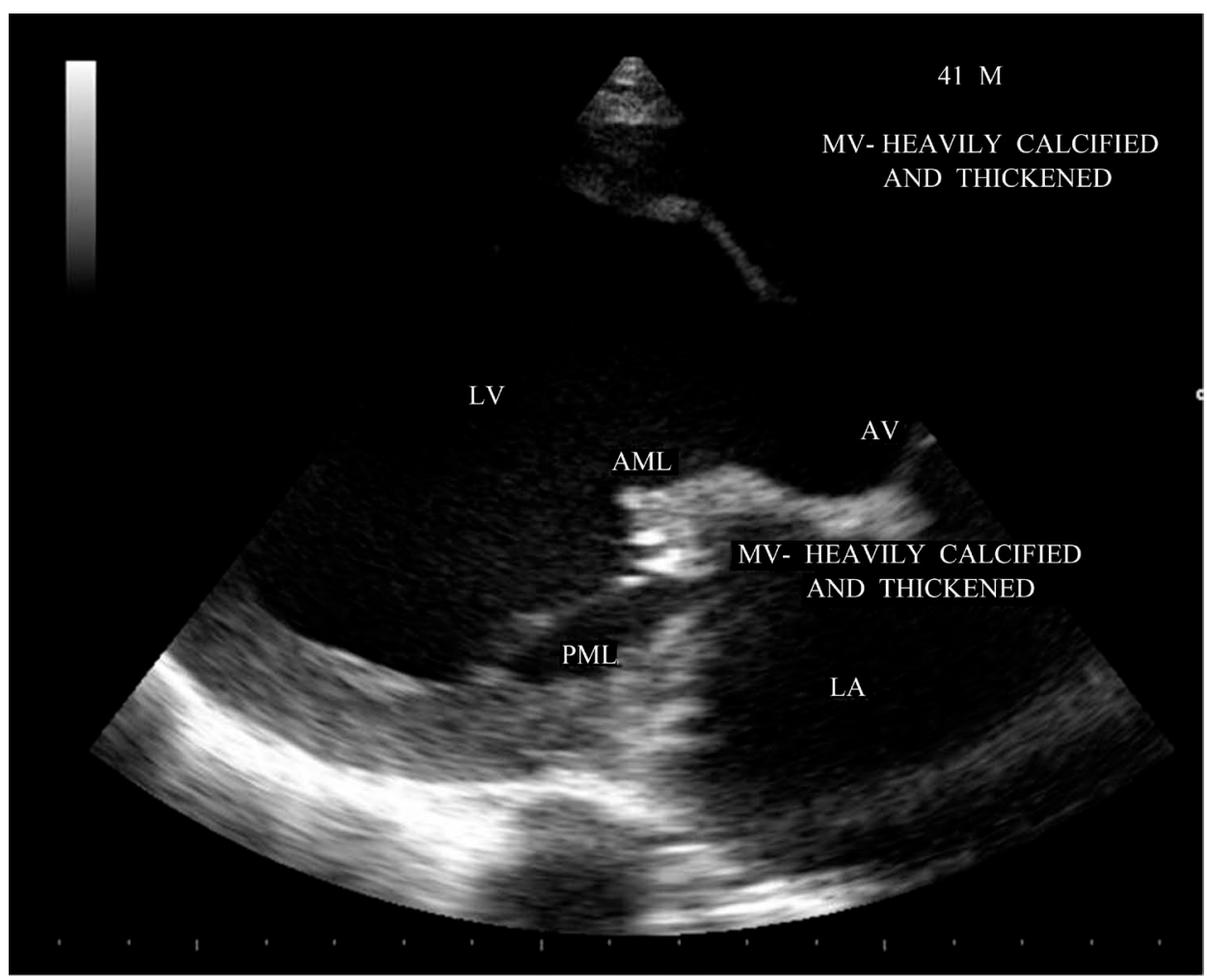

Figure 18. Parasternal long axis view showing the thickened and calcified mitral valve.

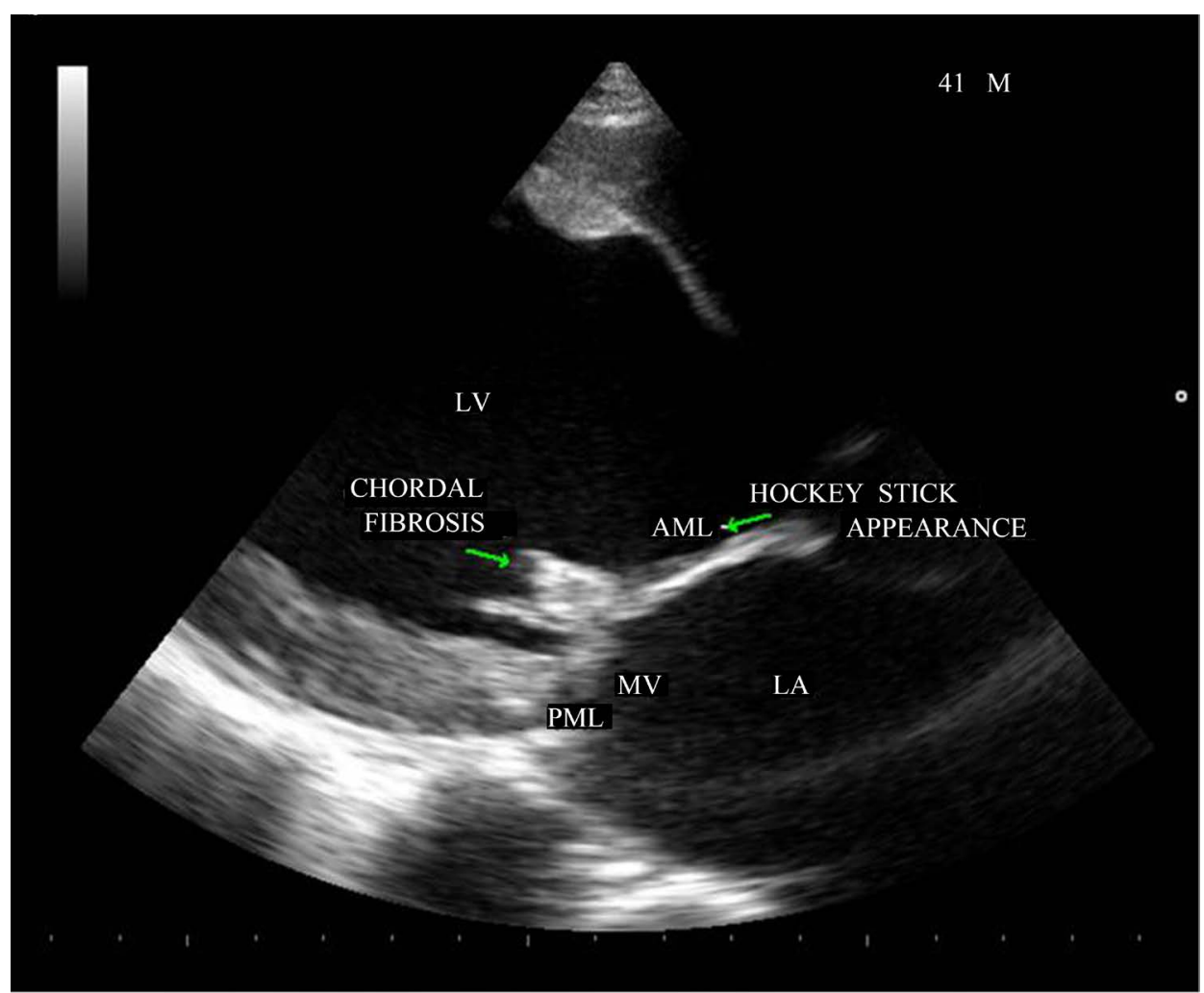

Figure 19. Parasternal long axis view in systole showing the diffuse thickening and fibrosis of chordal apparatus-less amenable to PMC) [24]. 


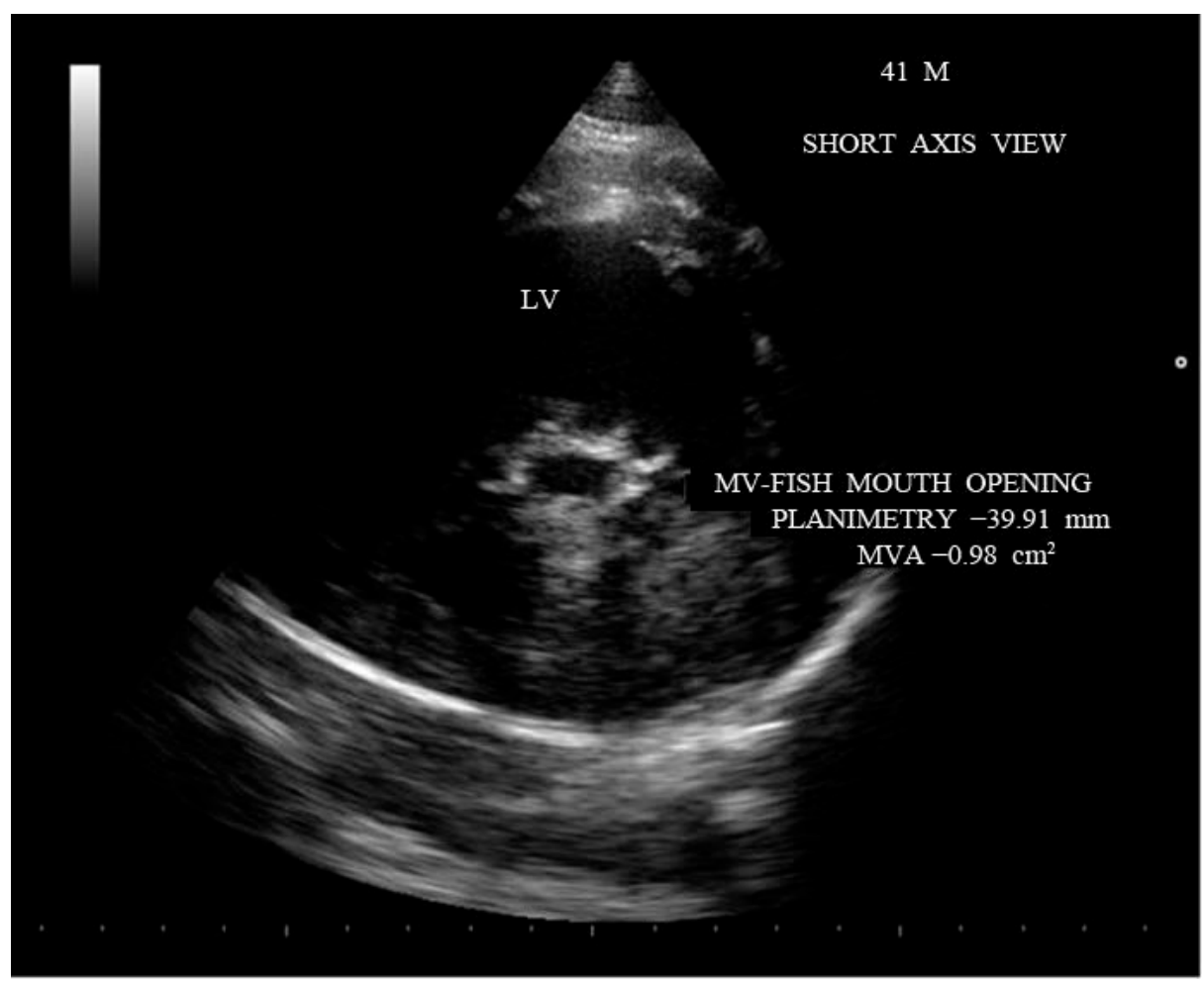

Figure 20. Short axis view showing the planimetry of mitral valve-circular orifice-MVA$0.98 \mathrm{~cm}^{2}$.

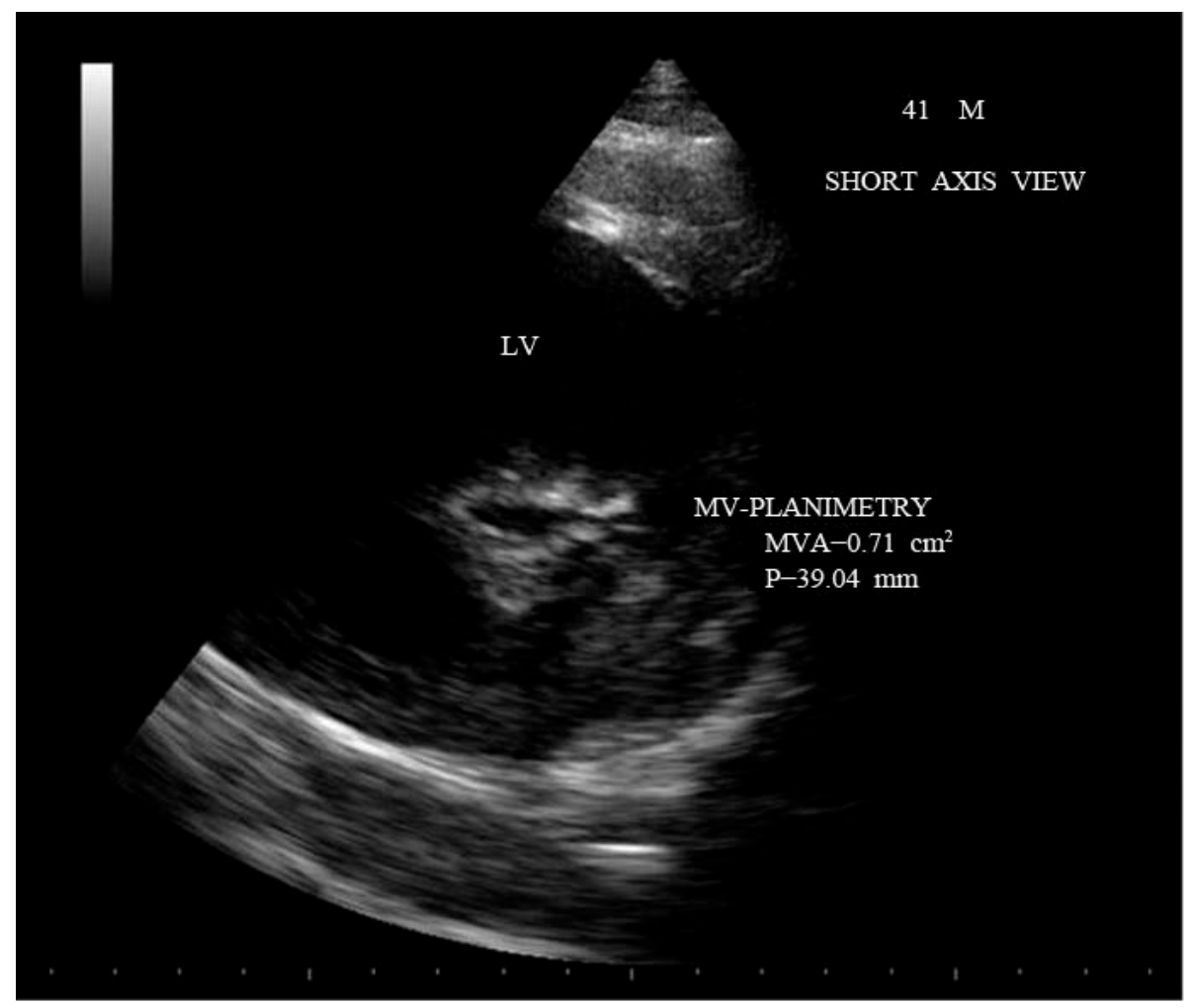

Figure 21. Short axis view showing the planimetry of mitral valve-slit like orifice-MVA$0.71 \mathrm{~cm}^{2}$. 


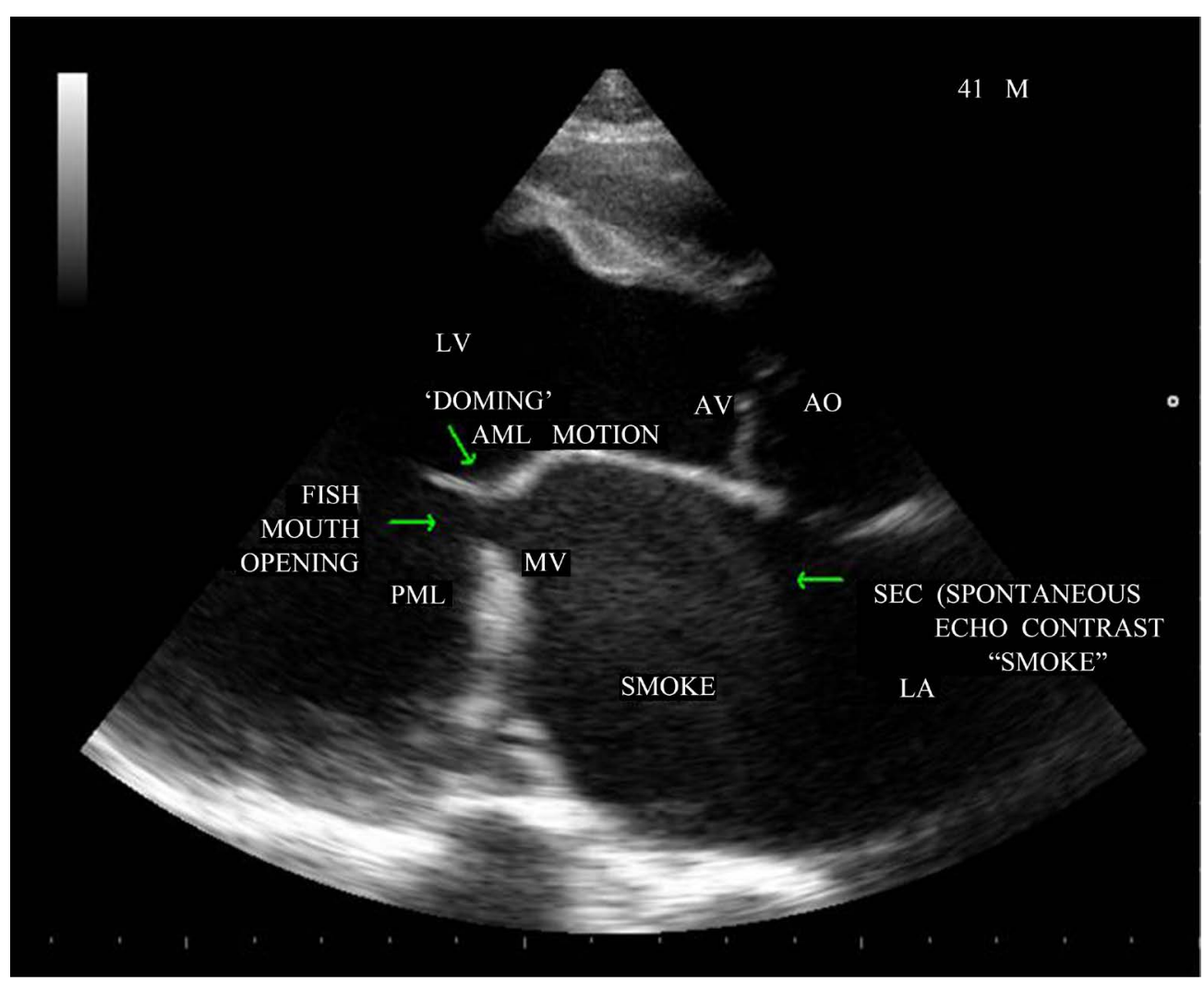

Figure 22. Parasternal long axis view showing the "smoke" in left atrial body.

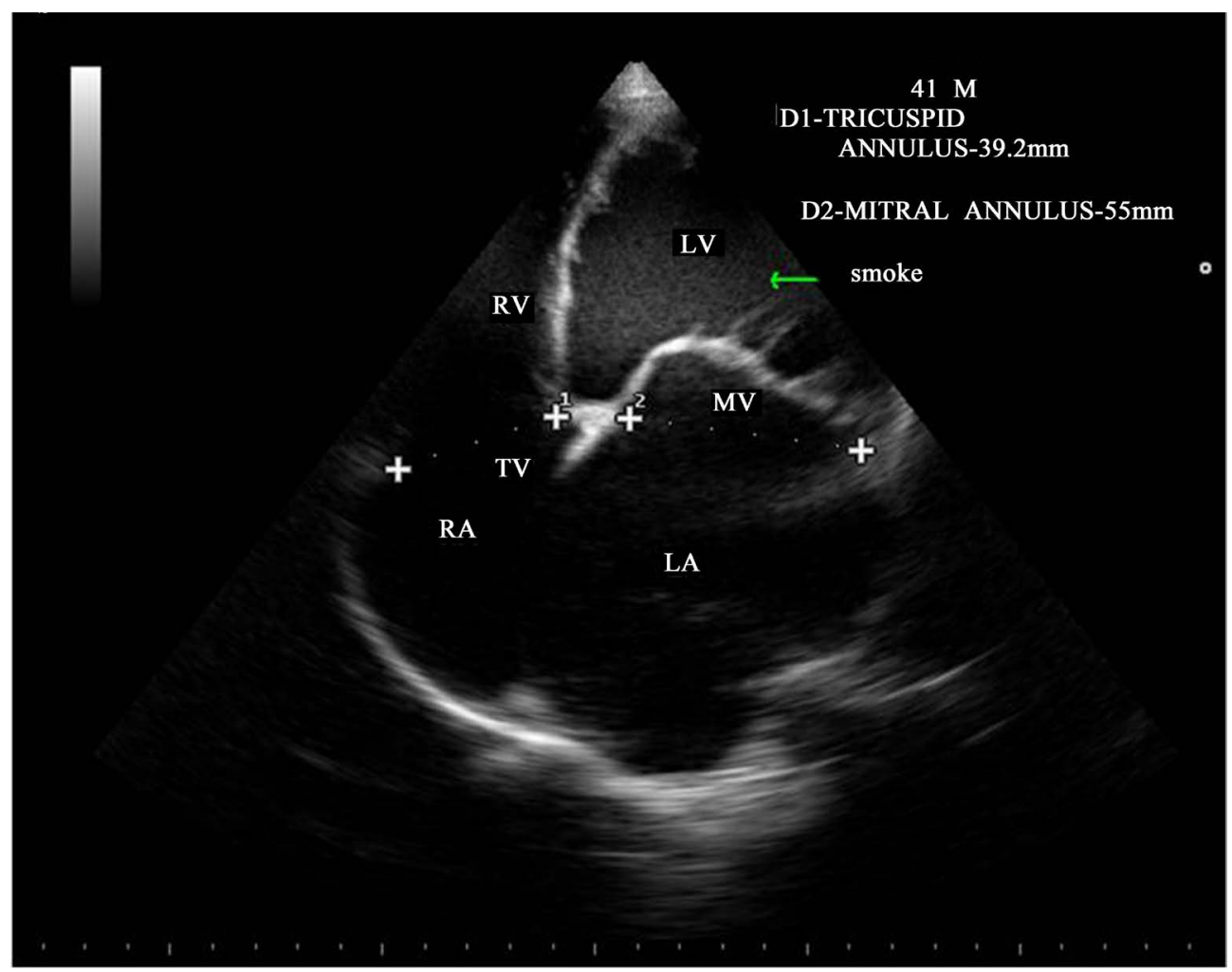

Figure 23. Apical four chamber view showing the "smoke" in the left ventricle. 


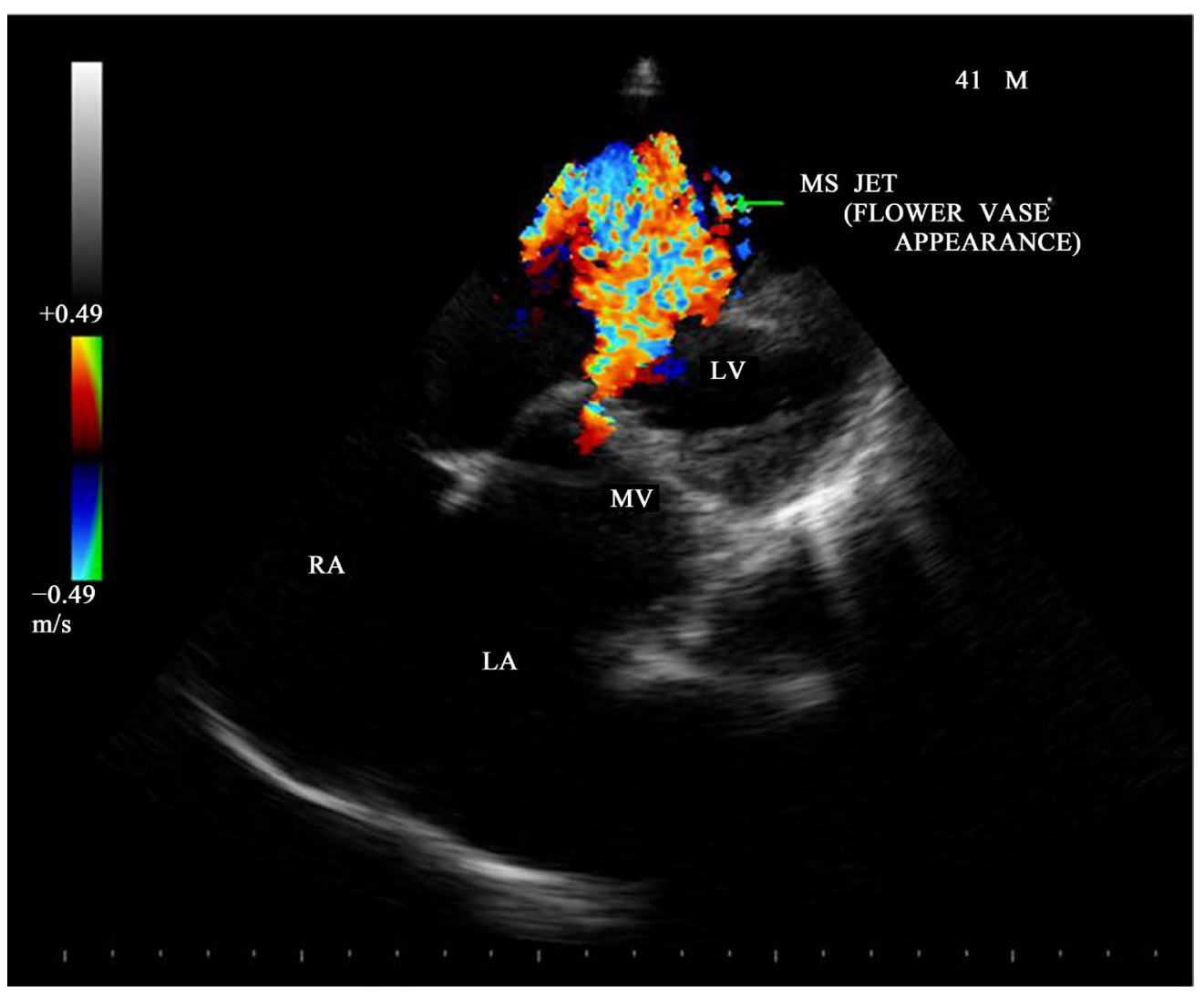

Figure 24. Apical four chamber view-showing the MS jet- “flower vase appearance”.

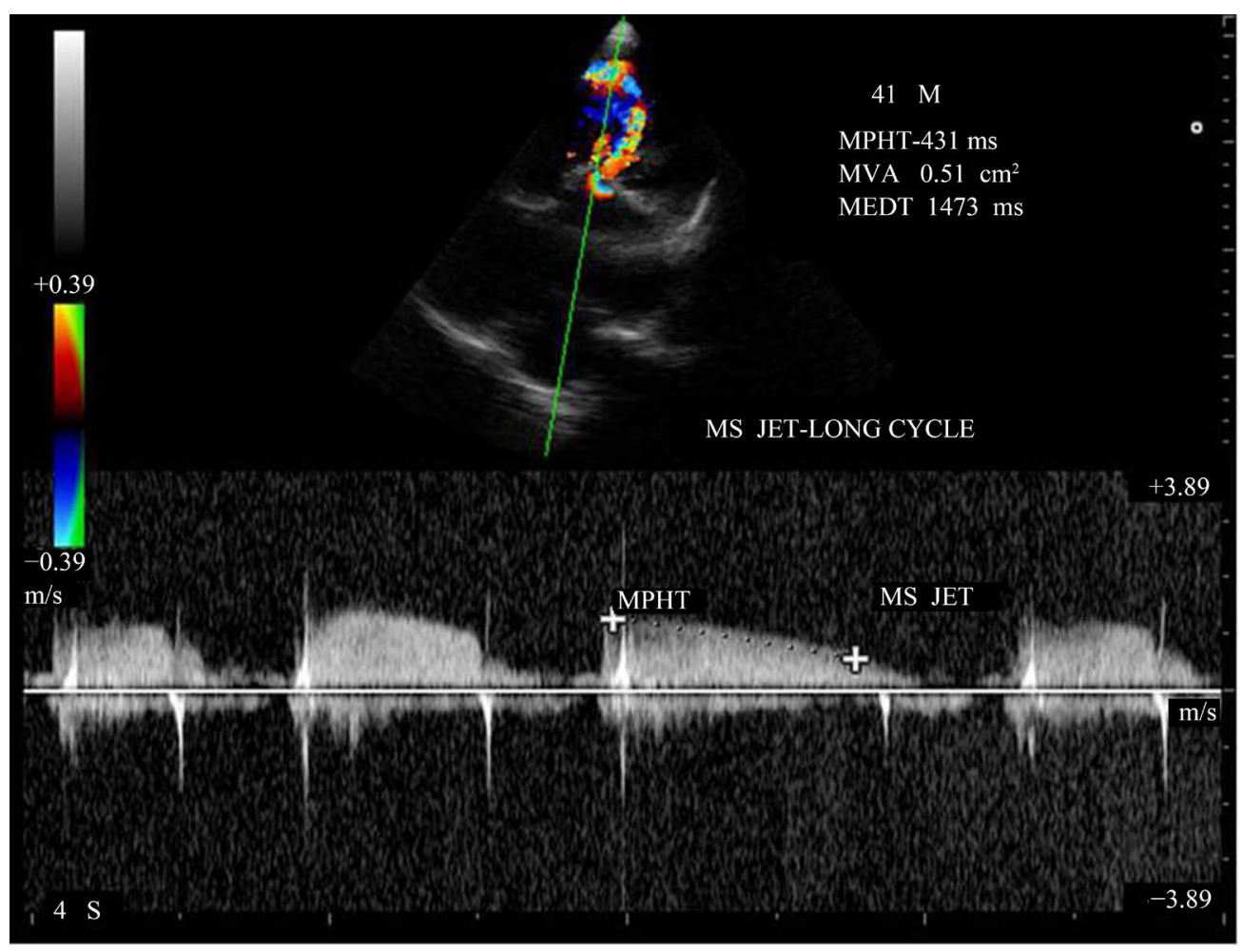

Figure 25. CW doppler showing the MS jet-long cycle pressure half-time. 


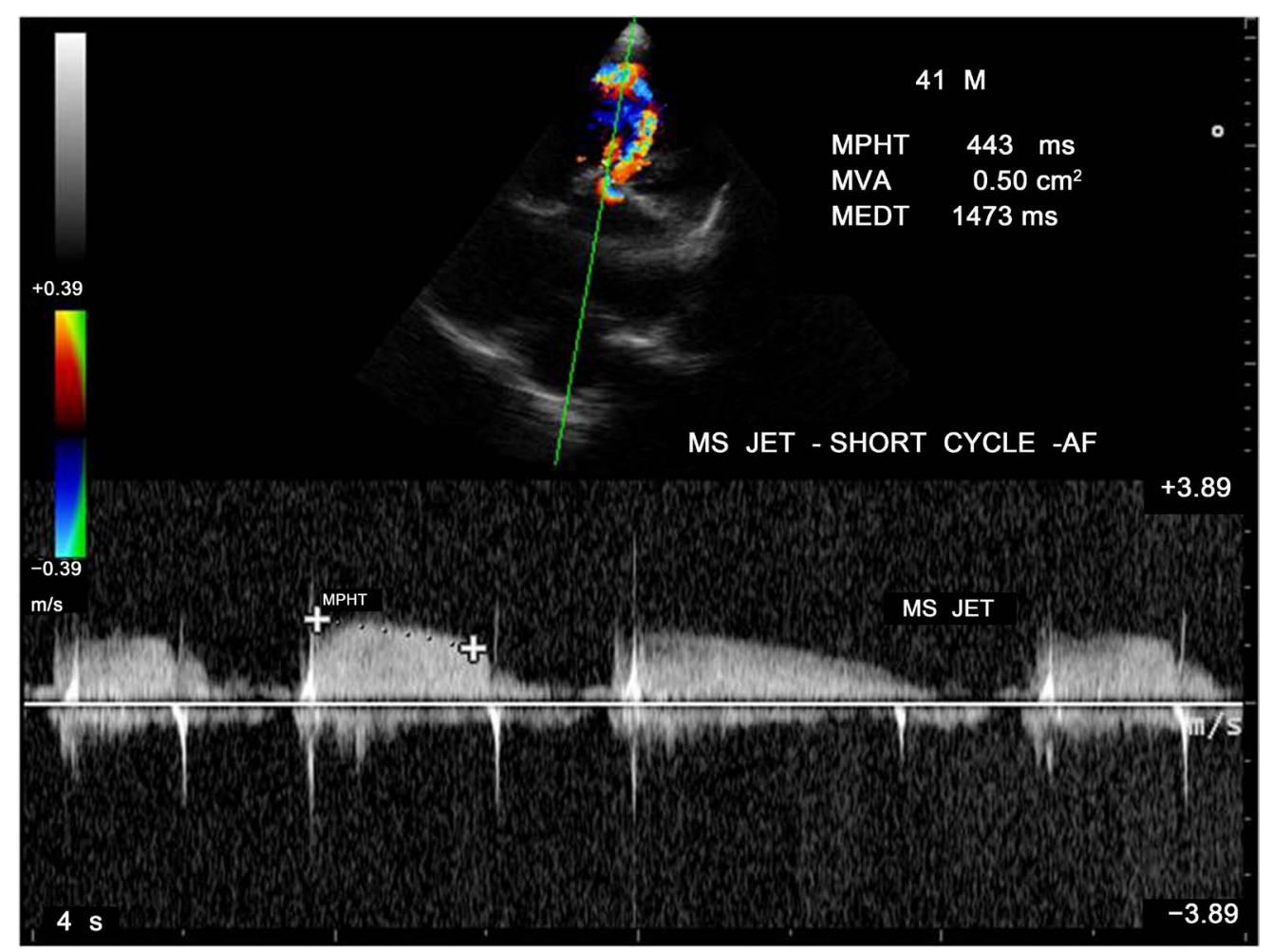

Figure 26. CW (continuous wave) doppler showing the MS jet- short cycle pressure half-time.

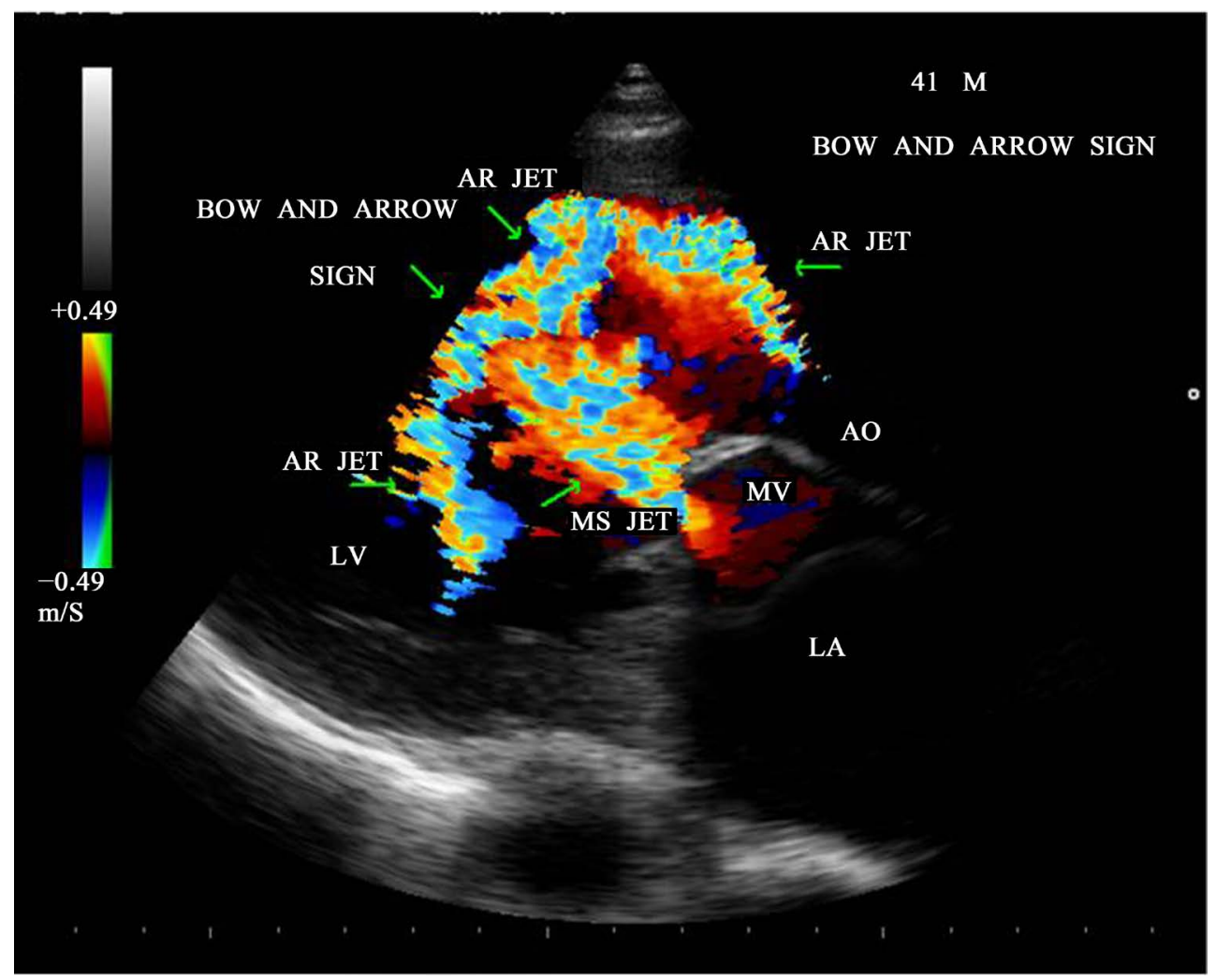

Figure 27. CW doppler showing the MS jet collide with AR jet and a "bow and arrow" appearance in parasternal long axis view. 


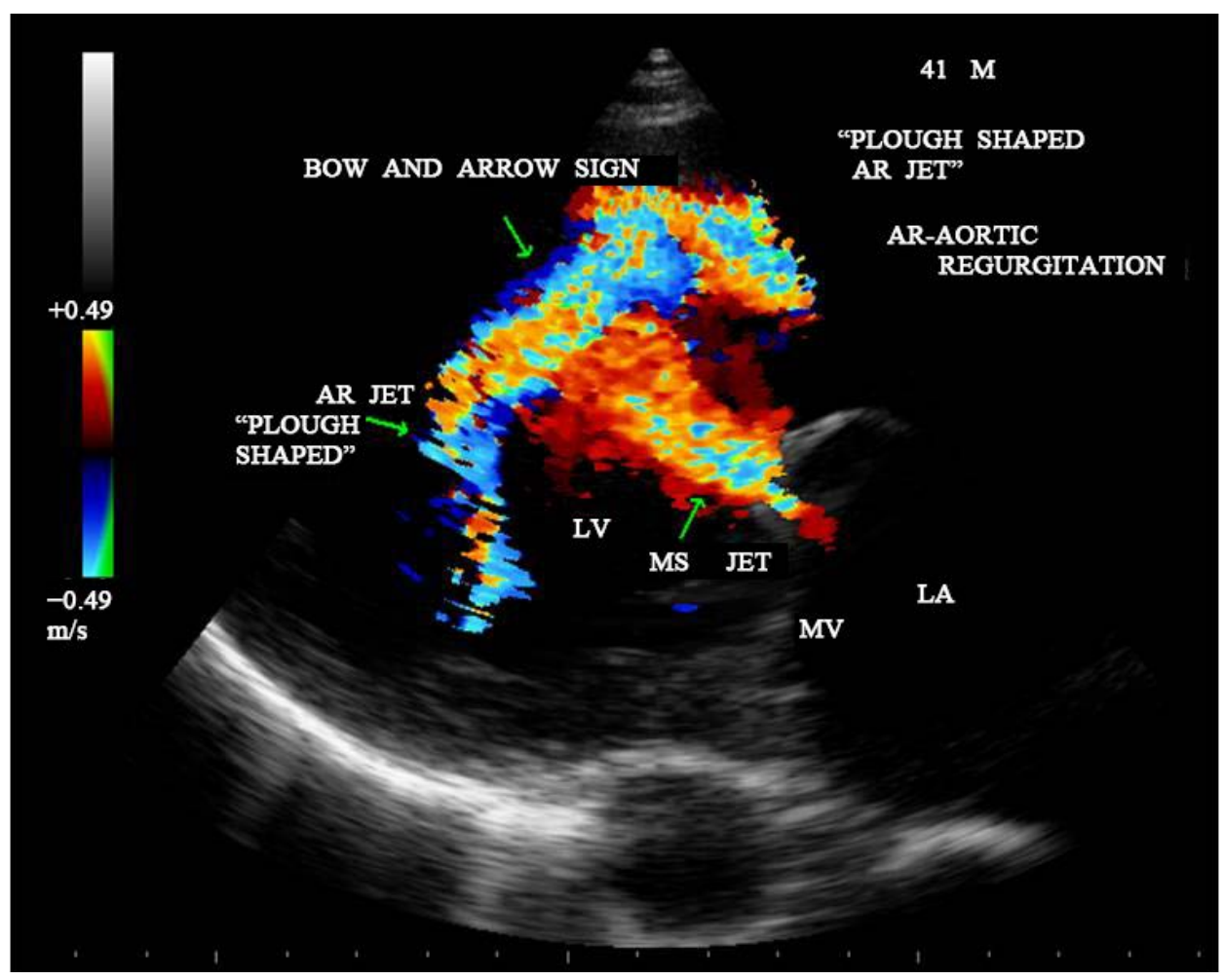

Figure 28. CW doppler showing the MS and AR jets-"bow and arrow sign” in parasternal long axis view- “plough" shaped AR jet.

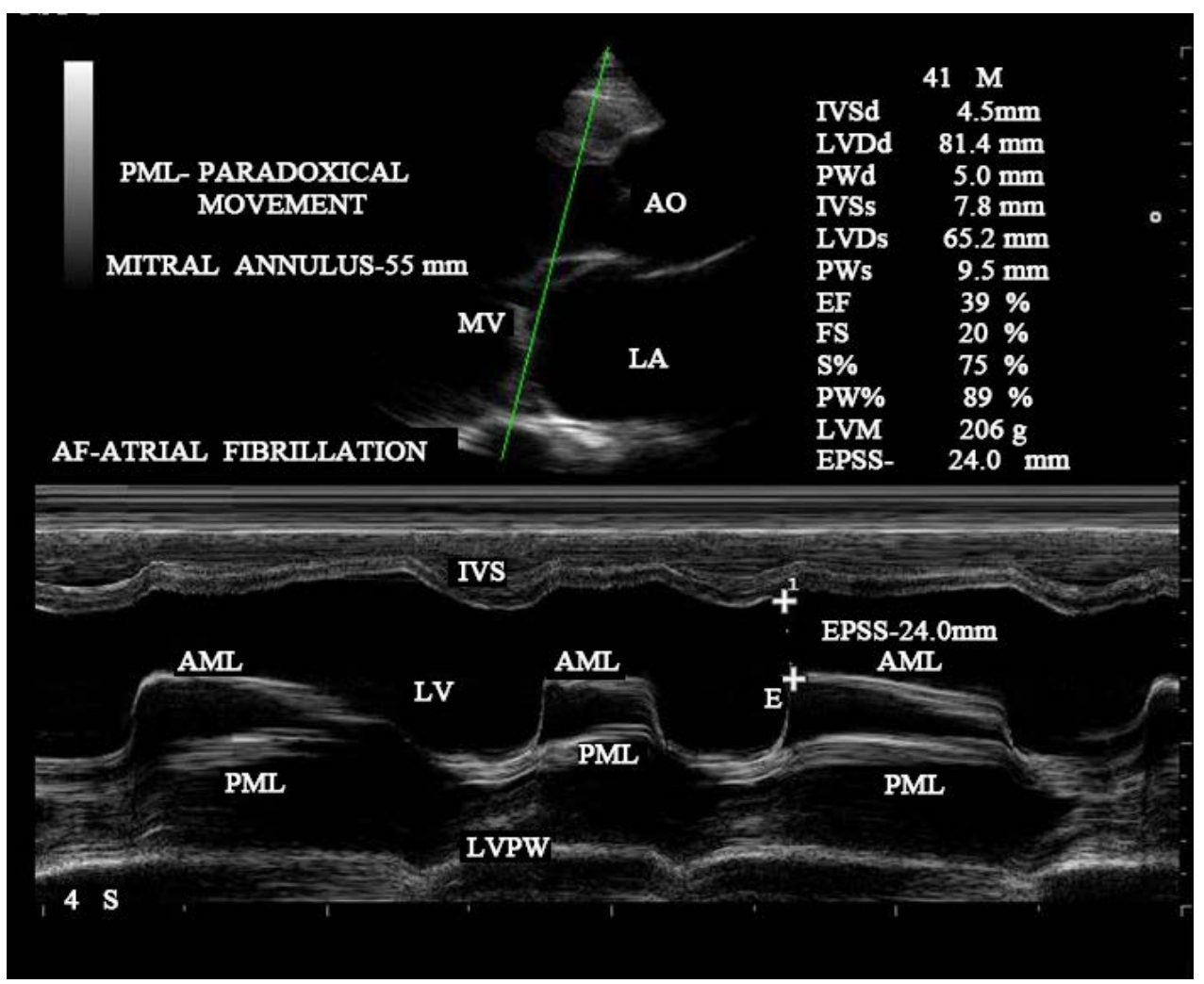

Figure 29. M-mode LV study, EPSS and paradoxical motion of posterior mitral leaflet. 


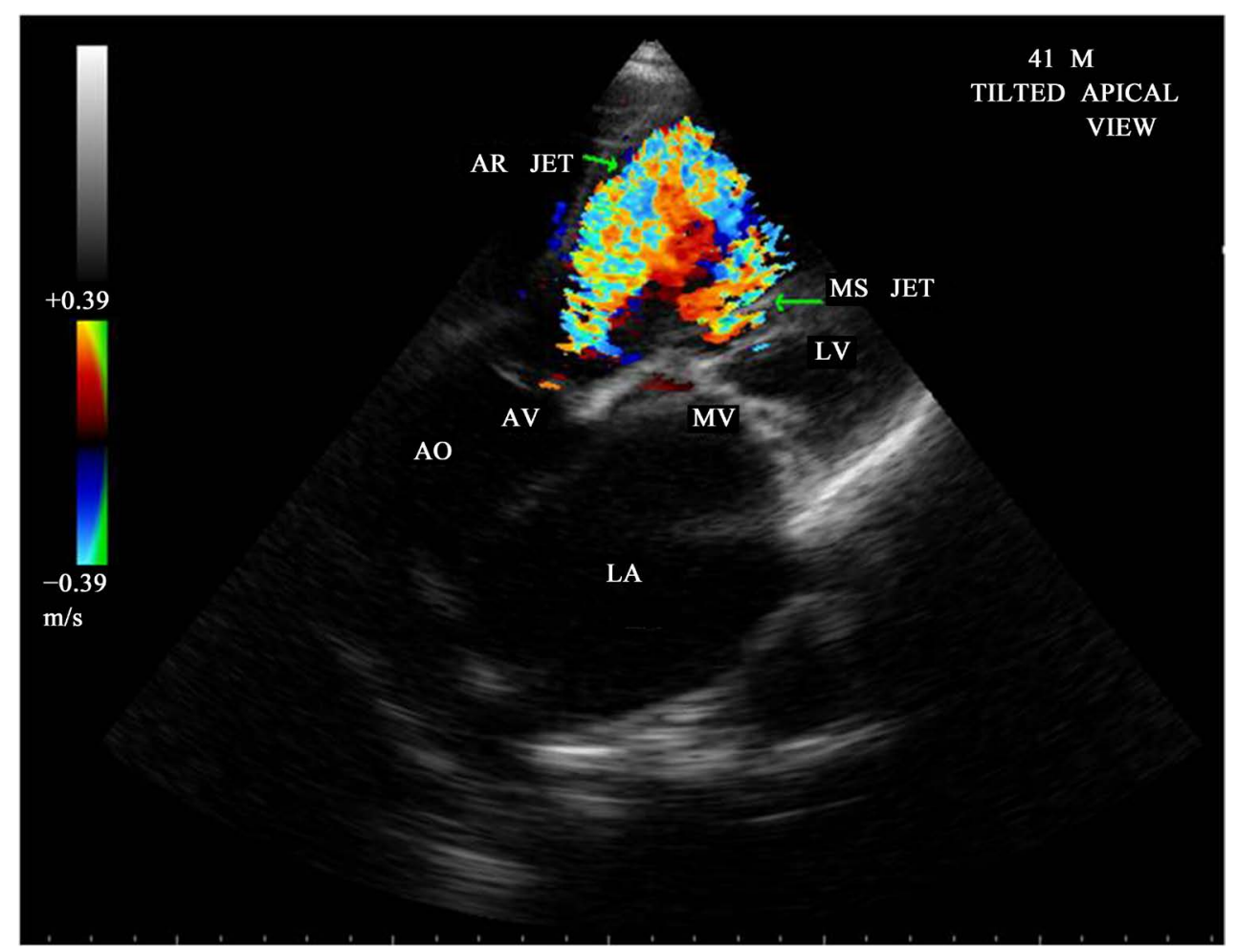

Figure 30. CW doppler showing the MS jet and AR jet in tilted apical view.

congenital bicuspid aortic valve, there are only two functional cusps, usually of unequal size, with the larger cusp having a midline raphe, resulting from incomplete commissural seperation during development. Less frequently, the cusps are of equal size and the raphe is absent. The raphe is frequently a major site of calcific deposits. The altered architecture of the bicuspid aortic valve induces turbulent flow with continuous trauma to the leaflets, ultimately resulting in fibrosis, increased rigidity, calcification and narrowing of the aortic orifice in adulthood [25]. Congenitally malformed tricuspid aortic valves with unequally sized cusps and commissural fusion called as "functionally bicuspid valves", can also cause turbulent flow leading to fibrosis and, ultimately, to calcification and stenosis. Clinical manifestations of congenital aortic stenosis in adults usually appear after the fourth decade of life. Stenotic bicuspid aortic valve comes to clinical attention at 50 - 70 years and senile calcific aortic stenosis of tricuspid valve at 70 - 90 years. Degenerative calcific aortic stenosis occurs as a consequence of long-standing hemodynamic stress on the valve and usually manifest in individuals older than 75 years with a prevalence of $2 \%$ - 9\% and occurs most frequently in males [26] having the risk factors of hypertension, hypercholesterolemia, diabetes mellitus, and smoking, due to active disease process at cellular and molecular level that shows many similarities with atherosclerosis, ranging from endothelial dysfunction to, ultimately calcification. The calcification may extend to mitral annulus and conduction system and produce conduction defects. The age-related degenerative ("wear and tear" of either of anatomically normal or congenital bicuspid ones) calcific aortic stenosis, there is dystrophic and passive accumulation of hydroxyapatite, the same calcium salt that is found in bone [27]. Chronic injury due to hypertension, hypercholesterolemia and inflammation in atherosclerosis differs as smooth muscle cell accumulation from the valve injury of calcific aortic stenosis in which abnormal valves contain cells resembling osteoblasts that synthesize bone matrix proteins and promote the deposition of calcium salts. BAV (bicuspid aortic valve) incur greater mechanical stress than the normal tricuspid valves, which may explain why they become stenotic more rapidly. The morphologic hallmark of non-rheumatic, calcific aortic stenosis (with either tricuspid or bicuspid aortic valve) is heaped-up calcified masses within the aortic cusps that ultimately protrude through the outflow surfaces into the sinus of valsalva and prevent the opening of the cusps. The free edges of the cusps are usually not involved and the commissural fusion is not found as in postrheumatic aortic valve stenosis. The calcific process begins in the valvular fibrosa at the point of maximal cusp flexion near the margin of the attachment and the layered architecture of the valve is largely preserved. 
Patients with bicuspid aortic valve may be completely asymptomatic. About $30 \%$ of individuals with a bicuspid aortic valve develop complications [28]. Occasionally, a congenital bicuspid aortic valve may be the cause of critical aortic stenosis, with symptoms of severe heart failure, developing in early infancy. This critical form of stenosis is more frequently associated with a unicommissural valve (severe form). The bicuspid aortic valve (moderate form) generally functions well in patients with left heart obstructive lesions such as coarctation or interrupted aortic arch and the incidence of bicuspid aortic valve is $>50 \%$ in these lesions. [29]. Stenosis of a bicuspid aortic valve is more likely to develop in persons older than 20 years and is caused by progressive sclerosis and calcification. High levels of serum cholesterol have been associated with more rapidly progressive sclerosis of the congenitally bicuspid aortic valve [30]. Children who develop early progressive pathologic changes in the bicuspid aortic valve are more likely to develop valve regurgitation than stenosis. Stenotic or partially fused valves may be caused by inflammatory process such as rheumatic fever.

There is a propensity for premature fibrosis, stiffening, and calcium deposition resulting in significant stenosis and cusp prolapse (due to redundancy of conjoined leaflet [31]), fibrotic retraction, or dilatation of the Sinotubular Junction resulting in Regurgitation in abnormally functioning congenital bicuspid aortic valves as "valvulopathy”. In addition, patients with poor lipid profile and those who smoke also act as an elevated rik of developing hemodynamically significant bicuspid aortic valve stenosis [32]. Aortopathy refers to dilated aortic root, usually associated with BAV and may lead to aortic aneurysm, dissection (the most feared complication-4\%) and rupture due to accelerated degeneration of the aortic media, indicating that BAV disease is an ongoing pathological process and not a discrete developmental event. Certain Gene mutations (NOTCH 1) have been implicated in fibrillin-1 deficiency in tissues. MMPs (matrix metalloproteinases) become activated, degrading the structural support of the aorta and medial weakness, resulting aortopathy in BAV. Recently, it is stated that identification of hemodynamics for leaflet fusion patterns enables detection of specific aortic regions susceptible to dysfunction. Variance in WSS (wall shear stress) and flow displacement are important in aortic leaflet morphology [33]. In BAV, helical and high velocity outflow patterns are consistent with aortic dilatation hemodynamics and RL fusion causes dilation of mid-ascending aorta, while RN fusion is associated with dilation in aortic root [34] as shown in Figure 11, distal ascending aorta and transverse arch are not dilated in this patient. Atherosclerotic aortic valve stenosis occur more frequently in patients with severe hypercholesterolemia and is observed in children with homozygous type II hyperlipoproteinemia [35] (total serum cholesterol >800 mg/dl from birth). Immunohistochemical evidence of chlamydia Pneumoniae has been found in early lesions of age related degenerative aortic stenosis [36].

Aortic valve may become bicuspid due to an acquired deformity of rheumatic process and have a fused commissure that produces a conjoined cusp as shown in Figure 4 and it is twice the size of nonconjoined cusp.

\subsection{Echocardiographic Features}

BAV is the most frequent congenital cardiovascular malformation in humans [37]. Bicuspid aortic valves are responsible for approximately 50\% of cases of aortic stenosis in adults [38]. In bicuspid aortic valve, two cusps are seen in systole with only two commissures framing an elliptical systolic orifice. Diastolic image may mimic a tricuspid valve when a raphe is present. Long axis view shows asymmetric closure line and systolic doming. In children and adolescents, it may be stenotic without extensive calcification. Calcification of tricuspid aortic valve is most pronounced in the central part of each cusp and commissural fusion is absent, resulting in a stellate-shaped systolic orifice. Rheumatic aortic stenosis is characterized by commissural fusion, resulting in a triangular systolic orifice with thickening and calcification most prominent along the edges of the cusps as shown in Figure 5.

\subsection{Types of Bicuspid Aortic Valve}

Bicuspid aortic valve may assume three different types of configuration [39]. Type-1——Real” bicuspid valve with two symmetric leaflets, Type-II-A tricuspid architecture with a fusion of two leaflets, Type-III-A tricuspid architecture with a fusion of 3 leaflets. Another classification described by Hans Sievens in 2007 based on the number of "cusps" and "raphes” as Type 0-no raphe (pure bicuspid aortic valve), Type-1—1 raphe, TypeII-2 raphes. "Raphe” is the arrow-shaped formation of tissues, also called "false commissures" and refer to the fused areas where the undeveloped cusps form a malformed commissure [40].

Demonstration of marked eccentricity of the aortic valve diastolic echoes with respect to the aortic lumen ap- 
pears to be the hallmark of a congenital bicuspid aortic valve. A normal tricuspid aortic valve, on the other hand, closes without cusp folding and therefore does not produce multiple diastolic echo sources along the lines of closure and the diastolic positions of cusp echoes is near the middle of the aortic lumen. In the case of the bicuspid aortic valve, the aortic valve diastolic position would be consistently observed near the anterior or near the posterior aortic margin depending on the location of the dominant leaflet. The eccentricity index denotes the deviation of the diastolic cusp position from the middle of the aortic lumen and takes into account the internal diameter of the aortic root. The index would equal unity if the valve cusps closed exactly in the center of the aortic root, while very high values (3.5 or above) would indicate extreme asymmetry of the cusp images. The eccentricity index was low, ranging from 1.0 to 1.25 in normal tricuspid aortic valve and high (1.5 to 5.6) in all patients with bicuspid aortic valve. The eccentricity index is 1.6 in this patient as shown in Figure 8 revealed the acquired rheumatic etiology for the bicuspid appearance in parasternal long axis view.

\subsection{Spontaneous Echo Contrast (SEC or "Smoke")}

Pathologic SEC (spontaneous echo contrast or "smoke") occurs when there is blood stasis due to low-flow velocity as a result of interaction between blood cells and plasma proteins, especially fibrinogen (eg. Rouleau formation) and it has been consistently associated with increased risk of thromboembolism. It is the swirling, hazy echocardiographic appearance as shown in Figure 22 and Figure 23, associated with low blood flow in mitral stenosis, atrial fibrillation and left ventricular failure. SEC usually occurs in the body of left atrium in mitral stenosis a shown in Figure 22. Atrial fibrillation in the absence of mitral stenosis is incapable of forming thrombus in the left atrial body [41]. Left atrial SEC is a better predictor of the thromboembolic risk than left atrial size [42]. Spontaneous echo contrast (SEC) is also seen in left ventricle (LV) in this patient as shown in Figure 23.

\subsection{Atrial Fibrillation}

Patients with atrial fibrillation in presence of structural heart disease such as mitral stenosis as shown in ECG in Figure 1 have high embolic potential and less likely to be maintained in sinus rhythm. The atrial fibrillation, a frequent sequelae of left atrial dilation due to mitral stenosis may cause SEC in LA appendage rather than in the body of left atrium. SEC may also occur in structurally normal heart with LAA (left atrial appendage) emptying flow velocity $<55 \mathrm{~cm} / \mathrm{s}$ (normal $\longrightarrow 50 \mathrm{~cm} / \mathrm{s}$ ) is associated elevated risk of thrombus formation. LAA emptying flow velocity $<35 \mathrm{~cm} / \mathrm{s}$ in atrial fibrillation is associated with elevated embolic risk (pulsed Doppler sample volume is placed in proximal third of appendage (mouth of appendage) in end-diastole).

\subsection{Aortic Regurgitation}

Another consequence of functionally normal bicuspid aortic valve is progressive regurgitation, and it is the most common cause of pure congenital aortic regurgitation [43]. Tricuspid aortic valves with cuspal inequality are seldom incompetent in the young, but become incompetent in older patients in whom minor degrees of fibrocalcification exaggerate inherent cuspal inequality and interfere with leaflet coaptation [44]. Rarely, a severely incompetent bicuspid aortic valve becomes stenotic with virtual loss of regurgitation [45]. The echocardiographic diagnosis can be difficult in patients with heavily calcified valves [46] and identification of aortic sinuses in short axis may helpful to predict the leaflet architecture. In normal tricuspid aortic valve, the three lines of coaptation forming a "Y" (sometimes referred to as inverted Mercedes-Benz sign). In bicuspid aortic valve, the raphe can make the valve appear trileaflet during diastole, and a characteristic "fish mouth appearance" of orifice as shown in Figure 6. Rheumatic fever produces fibrotic changes, thickening and retraction of the aortic valve leaflets, resulting in central valvular regurgitation [47] as shown in Figure 10. Leaflet fusion may occur, leading to concurrent aortic stenosis as shown in Figure 15. The pathophysiology depends on whether the regurgitation is acute or chronic. In acute AR (aortic regurgitation), LV (left ventricle) does not have time to dilate in response to the volume overload, the LV end-diastolic pressure increases rapidly and causing an increase in pulmonary venous pressure leading to pulmonary edema and cardiogenic shock in severe cases. In chronic AR, the left ventricle may undergo a series of adaptive changes due to gradual increase in volume overload. LV dilation occurs as shown in Figure 9 through the addition of sarcomeres in series and as a result, the LV becomes larger and more compliant, with greater capacity to deliver a large stroke volume. Due to increased preload and the FrankStarling mechanism, the ejection fraction (EF) is normal or even increased during early phase of chronic AR and 
the patient may remain asymptomatic during this period. When AR progresses, LV enlargement surpasses preload reserve and the ejection fraction falling to subnormal levels as shown in Figure 29 (LV EF-39\%, the LV end-systolic volume rises and it is a sensitive indicator of progressive myocardial dysfunction. Eventually, the $\mathrm{LV}$ reaches its maximal diameter and diastolic pressure begins to rise, resulting in symptoms of dyspnea which may worsen during exercise.

The severity of aortic regurgitation can be assessed by Doppler studies. It is stated that the length of AR jet penetration into the left ventricle is an unsatisfactory indicator of AR severity [48]. Due to massive LV dilation, AR jet falling into the dilated LV from a height of LVOT with an appearance of "water fall” as shown in Figure 12 and it correlates with severity of regurgitation in this patient. One of the simplest and most reliable is to measure the proximal regurgitation width (height) - immediately within $1 \mathrm{~cm}$ below the aortic valve and compared it to LVOT diameter (left ventricular outflow tract) [49] (measured from endocardial septum to anterior mitral leaflet within 0.5 - $1 \mathrm{~cm}$ below the aortic valve, parallel to aortic valve plane in mid-systole) and its ratio $\geq$ 65\% defines the severe AR and it cannot be used for eccentric jets. Figure 10 shows proximal AR jet width 20 $\mathrm{mm}$ and LVOT diameter $30 \mathrm{~mm}$ and its ratio is 66\%, suggesting severe AR in this patient.

\subsection{Vena Contracta}

It is the smallest neck of flow region at the level of the aortic valve, immediately below the flow convergence region and the threshold of vena contracta width associated with severe AR are $0.5 \mathrm{~cm}$ as a highly sensitive, 0.7 $\mathrm{cm}$ as a highly specific and $0.6 \mathrm{~cm}$ as the threshold with best combination of specificity and sensitivity [50]. To approximately visualize the vena contracta, it is essential to see all the components of the regurgitant flow, i.e., the flow convergence, vena contracta and the jet. The central jet tends to expand fully in the outflow tract as shown in Figure 10 and may be inconclusive to predict the vena contracta.

\subsection{Diastolic Jet Deceleration}

The rate of deceleration of diastolic regurgitant jet and the derived pressure half-time reflect the rate of equalization of aortic and LV diastolic pressures, with increasing severity of AR. The aortic diastolic pressure decreases more rapidly. The late diastolic jet velocity is lower and hence pressure half-time is shorter [51] and a ratio <200 $250 \mathrm{~ms}$ is consistent with severe AR and >500 ms with mild AR. On the other hand, pressure half-time can be lengthened or normalized with chronic LV adaptation to severe AR [52] as shown in Figure 15. In atrial fibrillation, the steeper slope of pressure decay in short cycle (PHT-194 ms) as shown in Figure 16 correlates with severity and the flat slope of pressure decay in long cycle (PHT-551 ms) as shown in Figure 15 is not correlating with severity of AR in this patient.

\subsection{Aortic Diastolic Flow Reversal}

A brief diastolic flow reversal in aorta is normal and it is best recorded at aortic isthmus level in the upper descending aorta by pulsed-wave doppler. With increasing aortic regurgitant, both the duration and velocity of reversal increase [53]. Therefore, a holodiastolic reversal as shown in Figure 17 is usually a more specific sign of at least moderate aortic regurgitation. Retrograde flow measured by pulsed-wave Doppler immediately after subclavian artery and if end diastolic flow velocity is $<18 \mathrm{~cm} / \mathrm{s}=$ does not indicate hemodynamically significant AR (grade I and II), $>18 \mathrm{~cm} / \mathrm{s}=$ indicate hemodynamically significant AR (grade III and IV). In severe cases, the initial diastolic flow velocity is $>0.6 \mathrm{~m} / \mathrm{s}$ and TVI backflow signal $>15 \mathrm{~cm}$. In this patient, the initial diastolic flow velocity is $0.80 \mathrm{~m} / \mathrm{s}$ and end diastolic velocity $0.22 \mathrm{~m} / \mathrm{s}$ correlate with severe aortic regurgitation. Holodiastolic flow reversal can be used to assess the aortic regurgitation following TAVR (Transcatheter aortic valve replacement-paravalvular leak).

Among the echocardiographic parameters, the ejection fraction (EF) and end-systolic dimension are the key determinants of outcome of surgery”.

\subsection{Coexistent Mitral Stenosis}

Acute insult of rheumatic fever on mitral valve leads to the formation of multiple inflammatory foci consists of Aschoff bodies, perivascular mononuclear infiltrate in the endocardium and myocardium. With time, the valve apparatus become thickened, calcified and contracted. Commissural adhesion occurs as shown in Figure 18 and 
ultimately resulting in mitral stenosis after a long latent period of streptococcal infection due to autoimmune mediated inflammation. Due to commissural fusion, the leaflets open with a "doming" motion as shown in Figure 9 and it results in reduction of the orifice and the conversion of the mitral leaflet-chordal apparatus from a tubular channel to a "funnel-shaped" orifice. The substantial fibrosis and calcification at the orifice of mitral valve limits inflow from left atrium to left ventricle and this limiting orifice is planimetered at the valve tips in mid-diastole as shown in Figure 20 and Figure 21, the orifice area correlate well with hemodynamic data and anatomic valve area [54].

In general, rheumatic mitral stenosis results in a central stenotic orifice with flow directed from the center of the left atrium towards the apex of the left ventricle and collide with AR jet, producing a "bow and arrow" appearance as shown in Figure 27 and Figure 28. The differential features of etiological aspects of mitral stenosis (MS) are shown in Table 1.

\subsection{Pressure Half-Time}

It is defined as the time interval in milliseconds between the maximum mitral gradient in early diastole and the time point where the gradient is half the maximum initial value. The decline of the velocity of diastolic transmitral flow is inversely proportional to valve area $\left(\mathrm{cm}^{2}\right)$ and MVA (mitral valve area) is derived by using the empirical formula (MVA $=220 / T_{1 / 2}$ ) [55]. The empirically determined constant of 220 is in fact proportional to the product of net compliance (i.e., the combined compliance of left atrium and LV) and the square root of maximum transmitral gradient in a model that does not take into account of active relaxation of LV [56]. In patients with Atrial Fibrillation, tracing should avoid mitral flow from short diastoles and average different cardiac

Table 1. Differential features of etiology of mitral stenosis (MS).

\begin{tabular}{lll}
\hline Rheumatic MS Degenerative MS & Dengenital MS \\
\hline
\end{tabular}

The main lesion is "commissural fusion"

Calcification predominates at leaflet tips

Planimetry is reliable

Pressure half-time reliable

Mean Gradient can be used following balloon mitral commissurotomy

Central or commissural jet due to valve stiffness.

Orifice is circular or elliptical in short axis view of planimetry.

Manifest in younger age group

Single orifice
The main lesion is "annular calcification". No commissural fusion

At base of leaflets

Not reliable

Unreliable due to impaired diastolic function and should be avoided

Mean Gradient can be used as a marker of severity

No particular orientation

Unpredictable

Manifest in older age group

Single orifice
Reliable when diastolic jet occurs

The main lesion is in "subvalvular apparatus". Commissural fusion is rare

Chordal fusion with calcification

Large orifice may be present

Reliable when diastolic jet occurs

Central jet in symmetric type. Eccentric jet in asymmetric type (anteriorily oriented jet in parachute type)

Chordal convergence' on a single papillary muscle in short axis view at mid-ventricular level in parachute type

Seen from birth

May present with “double orifice” type 
cycles as shown in Figure 25 and Figure 26, the mitral valve pressure half-time $=431 \mathrm{~ms}$ and Mitral valve area is $0.51 \mathrm{~cm}^{2}$ in long cycle and $443 \mathrm{~ms}$ and $0.50 \mathrm{~cm}^{2}$ in short cycle.

Aortic regurgitation causes the left ventricular pressure to increase more quickly in diastole than would otherwise occur. This can lead to shortening of pressure half-time and an underestimate of mitral stenosis severity. Early diastolic deceleration is prolonged when $\mathrm{LV}$ relaxation is impaired while it tends to be shortened in case of decreased LV compliance [57]. Rapid decrease in mitral velocity flow, i.e., short $\mathrm{T}_{1 / 2}$ can be observed despite severe MS in patients who have a particular low atrial compliance [58]. The deceleration slope is sometimes bimodal, the deceleration of mitral flow velocity being more rapid in early diastole than during the following part of the E-wave and in such cases, the deceleration slope in mid-diastole rather than the early deceleration slope be traced [59]. Planimetry is considered as the reference measurement of mitral valve area (MVA) [60]. The mitral valve areas measured by pressure half-time is $0.51 \mathrm{~cm}^{2}$ and $0.50 \mathrm{~cm}^{2}$ as shown in Figure 25 and Figure 26 are not correlated well with planimetry measurements as shown in Figure $20\left(0.98 \mathrm{~cm}^{2}\right)$ and $0.71 \mathrm{~cm}^{2}$ in Figure 21. The difference in planimetry measurements is due to positional variations, the point at which the orifice is planimetered [61]. Assessment of valve area using continuity equation and PISA (proximal isovelocity surface area) method are not recommended for routine use.

\subsection{M-Mode Findings of Mitral Stenosis}

The hallmark of rheumatic heart disease (RHD) was increased echogenicity of leaflets with decreased excursion and reduced separation of the anterior and posterior leaflets. There is "paradoxical" anterior diastolic motion of the posterior mitral leaflet as shown in Figure 29, due to tethering at the tips resulted in an obligatory anterior motion of the posterior mitral leaflet tips, that due to commissural fusion, were tethered to the larger anterior leaflet.

EPSS (E-point to septal separation)-EPSS is the distance ( $\mathrm{mm}$ ) from the anterior septal endocardium to the maximal early opening point (E-point) of the mitral valve and it is the first of M-mode findings to predict systolic dysfunction, an indirect measure of a reduced ejection fraction. The normal EPSS is $6 \mathrm{~mm}$ and a longer EPSS (24 mm as shown in Figure 29) represent a lower ejection fraction (EF-39\%). The ESD (end-systolic diameter-65.2 $\mathrm{mm}$ and LV dilation is $103 \mathrm{~mm}$ in this patient as shown in Figure 9 and Figure 29.

A patient with a low ejection fraction but a resting AS (aortic stenosis) velocity $>4 \mathrm{~m} / \mathrm{s}$ does not have a poor left ventricle. The ventricle is providing a normal response to high after load (severe AS), and ventricular function will improve after relief of stenosis. In this patient, a resting AS (aortic stenosis) velocity of $2.41 \mathrm{~m} / \mathrm{s}$ (PG$24 \mathrm{mmHg}$ ) as shown in Figure 15 with a low ejection fraction (39\%) indicating that the ventricle is poorly responding to high afterload. Absence of contractile reserve (failure to increase stroke volume or ejection fraction > $20 \%$ ) is a high surgical mortality and poor long-term outcome although valve replacement may improve LV function and outcome even in this subgroup [62].

\subsection{Low-Flow Low-Gradient Aortic Stenosis}

When LV systolic dysfunction co-exists with severe aortic stenosis, the AS velocity and gradient may be low despite a small valve area, a condition termed "low-flow low-gradient AS" and is characterized by effective orifice area $<1 \mathrm{~cm}^{2}$, LV ejection fraction $<40 \%$ and a mean pressure gradient $<30-40 \mathrm{mmHg}$.

The severity of aortic stenosis may be underestimated because decreased stroke volume due to mitral stenosis reduces the aortic gradient and may result in low cardiac output and therefore, low-flow low-gradient AS as shown in Figure 15.

In case of severe AR, the pressure half-time method for assessment of mitral stenosis is not valid. In severe AR, the left ventricle is more likely to become "full" so that the pressure half-time will be short with a poorly tolerated aortic valve insufficiency.

Severity assessment of rheumatic mitral stenosis should rely mostly on valve area $\left(<1 \mathrm{~cm}^{2}-\right.$ severe, $1-1.5$ $\mathrm{cm}^{2}$ - moderate, $>1.5 \mathrm{~cm}^{2}$-mild) and it is significant and symptomatic when MVA is $<1.5 \mathrm{~cm}^{2}$. It is specific, because of multiple factors influencing other supportive findings such as mean gradient $(<5 \mathrm{mmHg}-\mathrm{mild}, 5-$ $10 \mathrm{mmHg}$ - moderate, $>10 \mathrm{mmHg}$ - severe) and systolic pulmonary artery pressure ( $<30 \mathrm{mmHg}$ - mild, $30-50$ mmHg-moderate, $>50 \mathrm{mmHg}$ - severe). However, normal resting value of pulmonary artery pressure may be observed even in severe MS. A diameter of the tricuspid annulus $>40 \mathrm{~mm}$ seems to be more reliable than quantification of regurgitation to predict the risk of severe late TR after mitral surgery [63]. Tricuspid annulus diameter is $39.2 \mathrm{~mm}$ and mitral annulus diameter is $55 \mathrm{~mm}$ in this patient as shown in Figure 23 and reflecting no pulmonary hypertension. 
The echocardiographic scoring system (Wilkins score [64]) has been used as a valuable tool for patient selection to PMC (percutaneous mitral commissurotomy/or percutaneous balloon valvuloplasty). Impairment of mitral anatomy is expressed in scores combining different components of mitral apparatus or using an overall assessment of valve anatomy. Leaflet mobility, valvular thickening, valvular calcification, and subvalvular disease are each given a score of 0 - 4 and the total score is the sum of four items and ranges between 4 - 16. A total score of $<8$ results in good short and long-term outcome with balloon valvuloplasty. With higher scores $(>14)$ indicate more severe involvement and prefer valve replacement.

In Cormier score [65], it is grouped as Group 1 (pliable non-calcified anterior mitral leaflet with mid subvalvular disease i.e., thin chordae $\geq 10 \mathrm{~mm}$ long), Group II (pliable non-calcified anterior mitral leaflet and severe subvalvular disease i.e., thickened chordae $<10 \mathrm{~mm}$ long), Group III (calcification of mitral valve of any extent, as assessed by fluoroscopy whatever the state of subvalvular apparatus).

Echocardiographic parameters of this patient are shown in Table 2.

\subsection{Treatment}

Since the patient is having significant LV dysfunction and improving with antifailure measures, he was advised to continue the same line of management along with oral warfarin $2.5 \mathrm{mg}$ daily to maintain INR (International normalised ratio) between 2 to 3 and statin therapy (atorvastation $10 \mathrm{mg}$ daily). Patient is taking penicillin prophylaxis regularly every 3 weeks and advised for life long.

\subsection{Vasodilator Therapy}

Vasodilator therapy may be used to reduce after load in patients with systolic hypertension and chronic aortic regurgitation, in order to minimize wall stress and optimize LV function. However, in normotensive patients, vasodilator therapy is not likely to reduce regurgitant volume (preload) significantly and thus may not be of clinical benefit [66]. Vasodilators such as ACE (angiotensin-converting enzyme) inhibitors were not given due to intractable cough produced by these agents.

\subsection{Surgical Therapy}

If symptoms worsens, the patient may be referred for double valve replacement (both aortic and mitral valves) with mechanical prostheses since the LVEDD (left ventricular end-diastolic diameter) is $>70 \mathrm{~mm}$ [67], the EF (ejection fraction) is $<55 \%$, ESD (end-systolic diameter) is $>55 \mathrm{~mm}$ (the "55 rule" [68]-applicable even in asymptomatic patients).

When the diameter of aortic root is $>45 \mathrm{~mm}$, concurrent aortic root repair or replacement is indicated and it is not warranted since the aortic root is $43.2 \mathrm{~mm}$. Exclusion of coronary artery disease by angiography may be needed at the time of surgery since the age is 41 years.

Table 2. Echocardiographic parameters.

\begin{tabular}{|c|c|c|c|c|c|}
\hline \multicolumn{2}{|c|}{ 2D parameters } & \multicolumn{2}{|c|}{ M-mode parameters } & \multicolumn{2}{|c|}{ Doppler parameters } \\
\hline LV size & $103 \mathrm{~mm}$ & $\begin{array}{l}\text { LV end diastolic } \\
\text { diameter (LVEDD) }\end{array}$ & $81.4 \mathrm{~mm}$ & Aortic valve & Mitral valve \\
\hline LA size & $53 \mathrm{~mm}$ & $\begin{array}{l}\text { LV end systolic } \\
\text { diameter (LVESD) }\end{array}$ & $65.2 \mathrm{~mm}$ & AS jet & MS jet \\
\hline Mitral annulus & $55 \mathrm{~mm}$ & EPSS & $24 \mathrm{~mm}$ & $\begin{array}{l}\text { AS jet } 2.41 \mathrm{~m} / \mathrm{s} \\
\text { PG-23 mmHg }\end{array}$ & $\begin{array}{l}\text { PHT-431 ms-MVA-0.51 } \mathrm{cm}^{2} \text {-long } \\
\text { cycle }\end{array}$ \\
\hline Tricuspid annulus & $39.2 \mathrm{~mm}$ & & & AR jet & $\begin{array}{l}\text { MS PHT-443 ms-MVA-0.50 } \\
\text { cm²-short cycle }\end{array}$ \\
\hline Aortic annulus & $32.3 \mathrm{~mm}$ & & & $\begin{array}{l}\text { AR-PHT } 551 \text { ms-long cycle, } 194 \\
\text { ms-short cycle. AREDV-2.25m/s }\end{array}$ & Planimetry \\
\hline Aortic root & $42.2 \mathrm{~mm}$ & $\mathrm{EF}$ & $39 \%$ & $\begin{array}{l}\text { AR jet-holodiastolic flow reversal } \\
\text { Initial velocity- } 0.80 \mathrm{~m} / \mathrm{s} \\
\text { holodiastolic-ED velocity- } 0.22 \mathrm{~m} / \mathrm{s}\end{array}$ & $\begin{array}{c}\text { MVA-0.98 } \mathrm{cm}^{2} \text {-circular orifice } \\
\text { MVA-0.71 } \mathrm{cm}^{2} \text {-slit-like (elliptical) } \\
\text { orifice }\end{array}$ \\
\hline
\end{tabular}




\section{Conclusion}

This patient is having a congenital tricuspid aortic valve with cuspal inequality as shown in Figure 3 and it isseldom incompetent in the young. Rheumatic involvement of aortic valve creates a bicuspid architecture and the valve is regurgitant severely into the dilated left ventricle (LV) as a central jet falling into the LV with an appearance of a "water fall". It is associated with rheumatic mitral valve involvement creating a "hockey stick" deformity of anterior mitral leaflet with diffuse fibrosis of chordal apparatus resulting in severe stenosis with a central or commissural jet into the left ventricle in diastole and collide with AR (aortic regurgitation) jet and appeared as "bow and arrow" in echocardiography. Massive LV dilation and LA (left atrium) dilation lead to stasis of blood and producing "spontaneous echo contrasts" in both LA and LV is detected by 2D echocardiography imaging. The patient was advised double valve replacement (both aortic and mitral valve) and anticoagulant therapy with penicillin prophylaxis for life long.

\section{References}

[1] Carapetis, J.R., Steer, A.C., Mulholland, E.K. and Weber, M. (2005) The Global Burden of Goup A Steptococcal Diseases. The Lancet Infectious Diseases, 5, 685-694. http://dx.doi.org/10.1016/S1473-3099(05)70267-X

[2] Chockalingam, A., Gnanavelu, G., Elangovan, S. and Chockalingam, V. (2003) Clinical Spectrum of Chronic Rheumatic Heart Disease in India. Journal of Heart Valve Disease, 12, 577-581.

[3] Ba-Saddik, I.A., et al. (2011) Prevalence of Rheumatic Heart Disease among School-children in Aden, Yemen. Annals of Tropical Paediatrics, 31, 37-46. http://dx.doi.org/10.1179/1465328110Y.0000000007

[4] Ravisha, M.S., Tullu, M.S. and Kamat, J.R. (2003) Rheumatic Fever and Rheumatic Heart Disease. Clinical Profile of 550 cases in India. Archives of Medical Research, 34, 382-387. http://dx.doi.org/10.1016/S0188-4409(03)00072-9

[5] Brand, A., Dollberg, S. and Keren, A. (1992) The Prevalence of Valvular Regurgitation in Children with Structurally Normal Hearts. A Color Doppler Echocardiographic Study. American Heart Journal, 123, 177-180. http://dx.doi.org/10.1016/0002-8703(92)90763-L

[6] Keith, J.D., Rowe, R.D. and Vlad, P. (1978) Bicuspid Aortic Valve. In: Keith, J.D., Rowe, R.D. and Vlad, P., Eds., Heart Disease in Infancy and Childhood, MacMillan Publishing Co. Inc., New York, 728-735.

[7] Da Vinci, L. (1983) Leonardo on the Human Body. Dover Publications, New York.

[8] Sabet, H.Y., Edwards, W.D., Tazelaar, H.D. and Daly, R.C. (1999) Congenitally Bicuspid Aortic Valves: A Surgical Pathology Study of 542 Cases (1991 through 1996) and a Literature Review of 2,715 Additional Cases. Mayo Clinic Proceedings, 7491, 14-26. http://dx.doi.org/10.4065/74.1.14

[9] Peacock, T.B. (1858) On Malformations of the Human Heart. John Churchill, London.

[10] Brandenburg Jr., R.O., Tajik, A.J., Edwards, W.D., et al. (1983) Accuracy of 2-Dimensional Echocardiographic Diagnosis of Congenitally Bicuspid Aortic Valve. Echocardiographic-Anatomic Correlations in 115 Patients. American Journal of Cardiology, 51, 1469-1473. http://dx.doi.org/10.1016/0002-9149(83)90659-8

[11] Edler, I., Gustafson, A., Karlefors, T. and Christensson, B. (1961) Ultrasound Cardiography. Acta Medica Scandinavica, 170, 67-82.

[12] Gramiak, R. and Shah, P.M. (1968) Echocardiography of the Aortic Root. Investigative Radiology, 3, 356-366. http://dx.doi.org/10.1097/00004424-196809000-00011

[13] Titus, J.L., Edwards, J.E., Emery, R.W. and Arom, K.V. (1991) The Aortic Root and Valve. Anatomy and Congenital Anomalies. In: Emery, R.W. and Arom, K.V., Eds., The Aortic Valve, Hanley \& Belfus, Philadelphia, 1-8.

[14] Eisenberg, L.M. and Markwald, R.R. (1995) Molecular Regulation of Atrioventricular Valvuloseptal Morphogenesis. Circulation Research, 77, 1-6. http://dx.doi.org/10.1161/01.RES.77.1.1

[15] Fedeck, P.W., Verma, S., David, T.E., Leask, R.L., Weisel, R.D. and Butany, J. (2002) Clinical and Pathophysiogical Implications of a Bicuspid Aortic Valve. Circulation, 106, 900-904. http://dx.doi.org/10.1161/01.CIR.0000027905.26586.E8

[16] Lee, T.C., Zhao, Y.D., Courtman, D.W. and Stewart, D.J. (2000) Abnormal Aortic Valve Development in Mice Lacking Endothelial Nitric Oxide Synthase. Circulation, 101, 2345-2348. http://dx.doi.org/10.1161/01.CIR.101.20.2345

[17] Sans-Coma, V., Fernandez, B. and Duran, A.C. (1996) Fusion of Valve Cushions as a Key Factor in the Formation of Congenital Bicuspid Aortic Valves in Syrian Hamsters. Anatomical Record, 244, 490-498. http://dx.doi.org/10.1002/(SICI)1097-0185(199604)244:4<490::AID-AR7>3.0.CO;2-Z

[18] Kitchiner, D., Jackson, M. and Walsh, K., Peart, I. and Arnold, R. (1993) The Progression of Mild Congenital Aortic 
Valve Stenosis From Childhood into Adult Life. International Journal of Cardiology, 42, 217-223. http://dx.doi.org/10.1016/0167-5273(93)90051-H

[19] Ward, C. (2000) Clinical Significance of the Bicuspid Aortic Valve. Heart, 83, 81-85. http://dx.doi.org/10.1136/heart.83.1.81

[20] Michelena, H.I., Desjardins, V.A. and Avierinos, J.F. (2008) Natural History of Asymptomatic Patients with Normally Functioning or Minimally Dysfunctional Bicuspid Aortic Valve in the Community. Circulation, 117, 2776-2784. http://dx.doi.org/10.1161/CIRCULATIONAHA.107.740878

[21] Tzemos, N., Therrien, J. and Yip, J. (2008) Outcomes in Adults with Bicuspid Aortic Valves. JAMA, 300, $1317-1325$. http://dx.doi.org/10.1001/jama.300.11.1317

[22] Dare, A.J., Veinot, J.P., Edwards, W.D., et al. (1993) New Observations on the Etiology of Aortic Valve Disease. Human Pathology, 24, 1330-1338. http://dx.doi.org/10.1016/0046-8177(93)90267-K

[23] Chen, J., Okin, P.M., Roman, M.J., et al. (1996) Combined Rest and Exercise Electrocardiographic Repolarization Findings in Relation to Structural and Functional Abnormalities in Asymptomatic Aortic Regurgitation. American Heart Journal, 132, 343-347. http://dx.doi.org/10.1016/S0002-8703(96)90431-7

[24] Armstrong, W.F. and Feigenbaum, H. (2001) Echocardiography, Heart Disease, Text Book of Cardiovascular Medicine. 6th Edition, Chapter 7, Figure 7-48 (Bottom), Saunders, Philadelphia, 182.

[25] Braunwald, E., Goldblatt, A., Aygen, M.M., et al. (1963) Congenital Aortic Stenosis, Clinical and Hemodynamic Findings in 100 Patients. Circulation, 27, 426-462. http://dx.doi.org/10.1161/01.CIR.27.3.426

[26] Townsend, C.M., et al. (2008) The Course of Aortic Valve Disease, Sabiston Text Book of Surgery. 18th Edition, Saunders, New York, 1841-1844.

[27] Schoen, F.J. (2005) Cardiac Valves and Valvular Pathology, Update on Formation, Disease, Repair, and Replacement. Cardiovascular Pathology, 14, 189-194. http://dx.doi.org/10.1016/j.carpath.2005.03.005

[28] Beppu, S., Suzuki, S., Matsuda, H., et al. (1993) Rapidity of Progression of Aortic Stenosis in Patients with Congenital Bicuspid Aortic Valves. American Journal of Cardiology, 71, 322-327. http://dx.doi.org/10.1016/0002-9149(93)90799-I

[29] Duran, A.C., Frescura, C., Sans-Coma, V., et al. (1995) Bicuspid Aortic Valves in Hearts with Other Congenital Heart Disease. Journal of Heart Valve Disease, 4, 581-590.

[30] Chui, M.C., Newby, D.E., Panarelli, M., Bloomfield, P. and Boon, N.A. (2001) Association between Calcific Aortic Stenosis and Hypercholesterolemia: Is There a Need for a Randomized Controlled Trial of Cholesterol-Lowering Therapy? Clinical Cardiology, 24, 52-55. http://dx.doi.org/10.1002/clc.4960240109

[31] Roberts, W.C., Vowels, T.J. and Ko, J.M. (2012) Natural History of Adults with Congenitally Malformed Aortic Valves (Unicuspid or Bicuspid). Medicine (Baltimore), 91, 287-308. http://dx.doi.org/10.1097/MD.0b013e3182764b84

[32] Chan, K.-L., Ghani, M. and Woodend, K. (2001) Case-Controlled Study to Assess Risk Factors for Aortic Stenosis in Congenitally Bicuspid Aortic Valve. American Journal of Cardiology, 88, 690-693. http://dx.doi.org/10.1016/S0002-9149(01)01820-3

[33] Mahadevia, R., Barker, A.J., Schnell, S., et al (2014) Bicuspid Aortic Cusp Fusion Morphology alters Aortic ThreeDimensional Outflow Patterns, Wall Shear Stress, and Expression of Aortopathy. Circulation, 129, 673-682. http://dx.doi.org/10.1161/CIRCULATIONAHA.113.003026

[34] Hope, M.D, Hope, T.A., Meadows, A.K., et al. (2010) Bicuspid Aortic Valve: Four Dimensional MR (Magnetic Resonance) Evaluation of Ascending Aortic Systolic Flow Patterns. Radiology, 255, 53-61. http://dx.doi.org/10.1148/radiol.09091437

[35] Kawaguchi, A., Miyatake, K., Yutani, C., et al. (1999) Characteristic Cardiovascular Manifestations in Homozygous and Heterozygous Familial Hypercholesterolemia. American Heart Journal, 137, 410-418. http://dx.doi.org/10.1016/S0002-8703(99)70485-0

[36] Juvonen, J., Juvonen, T., Laurilia, A., et al. (1998) Can Degenerative Aortic Valve Stenosis Be Related to Persistent Chlamydia Pneumoniae Infection? Annals of Internal Medicine, 128, 741-744. http://dx.doi.org/10.7326/0003-4819-128-9-199805010-00007

[37] Braverman, A.C., et al. (2005) The Bicuspid Aortic Valve. Current Problems in Cardiology, 30, 470-522. http://dx.doi.org/10.1016/j.cpcardiol.2005.06.002

[38] Roberts, W.C. and Ko, J.M. (2005) Frequency by Decades of Unicuspid, Bicuspid and Tricuspid Aortic Valves in Adults Having Isolated Aortic Valve Replacement for Aortic Stenosis, with or without Associated Aortic Regurgitation. Circulation, 111, 920-925. http://dx.doi.org/10.1161/01.CIR.0000155623.48408.C5

[39] Anja, K. (2007) Bicuspid Aortic Valve. Klassifikation Bikuspider Aortenklappen. The Online Computer Library Center (OCLC) 254078723. 
[40] Aortic Surgery Program (1999-2015) Columbia University Medical Center, Department of Surgery, New York.

[41] Roberts, W.C. and Ko, J.M. (2008) Some Observations on Mitral and Aortic Valve Disease. Baylor University Medical Center Proceedings, 21, 282-299.

[42] Black, I.W., Hopkins, A.P., Lee, L.C. and Walsh, W.F. (1991) Left Atrial Spontaneous Echo Contrast: A Clinical and Echocardiographic Analysis. Journal of American College of Cardiology, 18, 398-404. http://dx.doi.org/10.1016/0735-1097(91)90592-W

[43] Sadee, A.S., Becker, A.E., Verheul, H.A., Bouma, B. and Hoedemaker, G. (1992) Aortic Valve Regurgitation and the Congenitally Bicuspid Aortic Valve. A Clinico-Pathological Correlation. British Heart Journal, 67, 439-441. http://dx.doi.org/10.1136/hrt.67.6.439

[44] Perloff, J.K. (2000) Physical Examination of the Heart and Circulation. 3rd Edition, WB (Walter Burns) Saunders, Philadelphia.

[45] Kalan,J.M., Mclntosh, C.L., Bonow, R.O. and Roberts, W.C. (1988) Development of Severe Stenosis in a Previously Purely Regurgitant Congenitally Bicuspid Aortic Valve. American Journal of Cardiology, 62, 988-989. http://dx.doi.org/10.1016/0002-9149(88)90912-5

[46] Chan, K.L., Stinson, W.A. and Veinot, J.P. (1999) Reliability of Transthoracic Echocardiography in the Assessment of Aortic Valve Morphology; Pathological Correlation in 178 Patients. Canadian Journal of Cardiology, 15, 48-52.

[47] Shoen, E.J. and St. John Sutton, M. (1991) Contemporary Pathologic Considerations in Valvular Disease. In: Virmani, R., Atkinson, J. and Fenoglio, J., Eds., Cardiovascular Pathology, WB (Walter Burns) Saunders Co., Philadelphia, 334-353.

[48] Perry, G.J., Helmcke, F., Nanda, N.C., Byard, C. and Soto, B. (1987) Evaluation of Aortic Insufficiency by Doppler Color Flow Mapping. Journal of American College of Cardiology, 9, 952-959. http://dx.doi.org/10.1016/S0735-1097(87)80254-1

[49] Reynolds, T., Abate, J., Tenney, A. and Warner, M.G. (1991) The JH/LVOH (Jet Height/Left Ventricular Outflow Tract Height) Method in the Quantification of Aortic Regurgitation: How the Cardiac Sonographer May Avoid an Important Potential Pitfall. Journal of American Society of Echocardiography, 4, 105-108. http://dx.doi.org/10.1016/S0894-7317(14)80521-X

[50] Tribouilloy, C.M., Enriquez Sarano, M., Bailey, K.R., Seward, J.B. and Tajik, A.J. (2000) Assessment of Severity of Aortic Regurgitation Using the Width of the Vena Contracta: A Clinical Color Doppler Imaging Study. Circulation, 102, 558-564. http://dx.doi.org/10.1161/01.CIR.102.5.558

[51] Teague, S.M., Heinsimer, J.A., Anderson, J.L., et al. (1986) Quantification of Aortic Regurgitation Utilizing Continuous Wave Doppler Ultrasound. Journal of American College of Cardiology, 8, 592-599. http://dx.doi.org/10.1016/S0735-1097(86)80188-7

[52] Griffin, B.P., Flachskampf, F.A., Siu, S., Weyman, A.E. and Thomas, J.D. (1991) The Effects of Regurgitant Orifice Size, Chamber Compliance, and Systemic Vascular Resistance on Aortic Regurgitant Velocity Slope and Pressure Half-Time. American Heart Journal, 122, 1049-1056. http://dx.doi.org/10.1016/0002-8703(91)90471-S

[53] Touche, T., Prasquier, R., Nitenberg, A., de Zuttere, D. and Gourgon, R. (1985) Assessment and Follow-Up of Patients with Aortic Regurgitation by an Updated Doppler Echocardiographic Measurement of the Regurgitant Fraction in the Aortic Arch. Circulation, 72, 819-824. http://dx.doi.org/10.1161/01.CIR.72.4.819

[54] Faletra, F., Pezzano Jr., A., Fusco, R., Mantero, A., Corno, R., Crivellaro, W., et al. (1996) Measurement of Mitral Valve Area in Mitral Stenosis: Four Echocardiographic Methods Compared with Direct Measurement of Anatomic Orifices. Journal of American College of Cardiology, 28, 1190-1197. http://dx.doi.org/10.1016/S0735-1097(96)00326-9

[55] Thomas, J.D. and Weyman, A.E. (1987) Doppler Mitral Pressure Half-Time: A Clinical Tool in Search of Theoretical Justification. Journal of American College of Cardiology, 10, 923-929. http://dx.doi.org/10.1016/S0735-1097(87)80290-5

[56] Thomas, J.D., Wilkins, G.T., Choong, C.Y., Abascal, V.M., Palacios, I.F., Block, P.C., et al. (1988) Inaccuracy of Mitral Pressure Half-Time Immediately after Percutaneous Mitral Valvotomy. Dependence on Transmitral Gradient and Left Atrial and Ventricular Compliance. Circulation, 78, 980-993. http://dx.doi.org/10.1161/01.CIR.78.4.980

[57] Karp, K., Teien, D., Bjerle, P. and Eriksson, P. (1989) Reassessment of Valve Area Determination in Mitral Stenosis by the Pressure Half-Time Method: Impact of Left Ventricular Stiffness and Peak Diastolic Pressure Difference. Journal of American College of Cardiology, 13, 594-599. http://dx.doi.org/10.1016/0735-1097(89)90599-8

[58] Schwammenthal, E., Vered, Z., Agranat, O., Kaplinsky, E., Rabinowitz, B. and Feinberg, M.S. (2000) Impact of Atrioventricular Compliance on Pulmonary Artery Pressure in Mitral Stenosis: An Exercise Echocardiographic Study. Circulation, 102, 2378-2384. http://dx.doi.org/10.1161/01.CIR.102.19.2378

[59] Gonzalez, M.A., Child, J.S. and Krivokapich, J. (1987) Comparison of Two-Dimensional and Doppler Echocardiogra- 
phy and Intracardiac Hemodynamics for Quantification of Mitral Stenosis. American Journal of Cardiology, 60, 327332. http://dx.doi.org/10.1016/0002-9149(87)90236-0

[60] Vahanian, A., Baumgartner, H., Bax, J., Butchart, E., Dion, R., Filippatos, G., et al. (2007) Guidelines on the Management of Valvular Heart Disease. The Task Force on the Management of Valvular Heart Disease of the European Society of Cardiology. European Heart Journal, 28, 230-268

[61] Feigenbaum, H., Armstrong, W.F. and Ryan, T. (2005) Mitral Valve Disease. In: Alpert, J.S., Dalen, J.E., Rahimtoala, S.H., Eds., Feigenbaum's Echocardiography, 6th Edition, Lippincott Williams and Wilkins Company, Philadelphia, 313-317.

[62] Monin, J.L., Quere, J.P., Monchi, M., Petit, H., Baleynaud, S., Chauvel, C., et al. (2003) Low-Gradient Aortic Stenosis: Operative Risk Stratification and Predictors for Long-Term Outcome. A Multicenter Study Using Dobutamine Stress Hemodynamics. Circulation, 108, 319-324. http://dx.doi.org/10.1161/01.CIR.0000079171.43055.46

[63] Dreyfus, G.D., Corbi, P.J., Chan, K.M. and Bahrami, T. (2005) Secondary Tricuspid Regurgitation or Dilatation: Which Should Be the Criteria for Surgical Repair? Annals of Thoracic Surgery, 79, 127-132. http://dx.doi.org/10.1016/j.athoracsur.2004.06.057

[64] Wilkins, G.T., Weyman, A.E., Abascal, V.M., Block, P.C. and Palacios, I.F. (1988) Percutaneous Balloon Dilatation of the Mitral Valve: An Analysis of Echocardiographic Variables Related to Outcome and the Mechanism of Dilatation. British Heart Journal, 60, 299-308. http://dx.doi.org/10.1136/hrt.60.4.299

[65] Lung, B., Cormier, B., Ducimetiere, P., Porte, J.M., Nallet, O. and Michel, P.L., et al. (1996) Immediate Results of Percutaneous Mitral Commissurotomy. A Predictive Model on a Series of 1514 Patients. Circulation, 94, 2124-2130. http://dx.doi.org/10.1161/01.CIR.94.9.2124

[66] Bekeredjian, R. and Grayburn, B.A. (2005) Valvular Heart Disease: Aortic Regurgitation. Circulation, 112, $125-134$. http://dx.doi.org/10.1161/CIRCULATIONAHA.104.488825

[67] Vahanian, A., Alfieri, O., Andreotti, F., Antunes, M.J., Baron-Esquivias, G., Baumgartner, H., et al. (2012) Guidelines on the Management of Valvular Heart Disease. The Joint Task Force on the Management of Valvular Heart Disease of the European Society of Cardiology (ESC) and the European Association for Cardio-Thoracic Surgery (EACTS). European Heart Journal, 33, 2451-2496. http://dx.doi.org/10.1093/eurheartj/ehs109

[68] Carabello, B.A. and Crawford Jr., F.A. (1997) Valvular Heart Disease. New England Journal of Medicine, 337, 32-41. http://dx.doi.org/10.1056/NEJM199707033370107

\section{Submit or recommend next manuscript to SCIRP and we will provide best service for you:}

Accepting pre-submission inquiries through Email, Facebook, LinkedIn, Twitter, etc.

A wide selection of journals (inclusive of 9 subjects, more than 200 journals)

Providing 24-hour high-quality service

User-friendly online submission system

Fair and swift peer-review system

Efficient typesetting and proofreading procedure

Display of the result of downloads and visits, as well as the number of cited articles

Maximum dissemination of your research work

Submit your manuscript at: http://papersubmission.scirp.org/ 